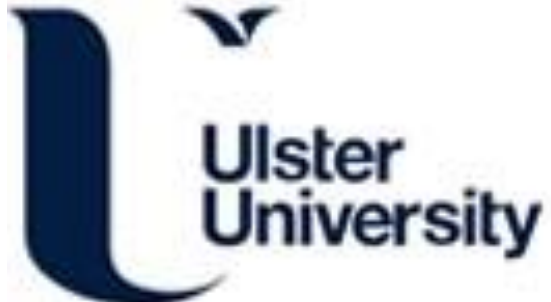

\section{Electroneutral polymersomes for combined cancer chemotherapy}

Aibani, N., Nesbitt, H., Marino, N., Jurek, J., O'Neill, C., Martin, C., Di Bari, I., Sheng, Y., Logan, K., Hawthorne, S., McHale, A. P., Callan, J. F., \& Callan, B. (2018). Electroneutral polymersomes for combined cancer chemotherapy. Acta Biomaterialia, 80, 327-340. https://doi.org/10.1016/j.actbio.2018.09.005

Link to publication record in Ulster University Research Portal

\section{Published in:}

Acta Biomaterialia

Publication Status:

Published (in print/issue): 15/10/2018

DOI:

10.1016/j.actbio.2018.09.005

\section{Document Version}

Author Accepted version

\section{General rights}

Copyright for the publications made accessible via Ulster University's Research Portal is retained by the author(s) and / or other copyright owners and it is a condition of accessing these publications that users recognise and abide by the legal requirements associated with these rights.

\section{Take down policy}

The Research Portal is Ulster University's institutional repository that provides access to Ulster's research outputs. Every effort has been made to ensure that content in the Research Portal does not infringe any person's rights, or applicable UK laws. If you discover content in the Research Portal that you believe breaches copyright or violates any law, please contact pure-support@ulster.ac.uk. 


\section{Accepted Manuscript}

Full length article

Electroneutral polymersomes for combined cancer chemotherapy

Noorjahan Aibani, Heather Nesbitt, Nino Marino, Joanna Jurek, Caolin O'Neill, Chloe Martin, Ivana Di Bari, Yingjie Sheng, Kieran Logan, Susan Hawthorne, Anthony McHale, John F. Callan, Bridgeen Callan

PII: S1742-7061(18)30522-1

DOI: https://doi.org/10.1016/j.actbio.2018.09.005

Reference: ACTBIO 5649

To appear in: Acta Biomaterialia

Received Date: $\quad 15$ May 2018

Revised Date: $\quad 3$ September 2018

Accepted Date: $\quad 6$ September 2018

Please cite this article as: Aibani, N., Nesbitt, H., Marino, N., Jurek, J., O'Neill, C., Martin, C., Di Bari, I., Sheng, Y., Logan, K., Hawthorne, S., McHale, A., Callan, J.F., Callan, B., Electroneutral polymersomes for combined cancer chemotherapy, Acta Biomaterialia (2018), doi: https://doi.org/10.1016/j.actbio.2018.09.005

This is a PDF file of an unedited manuscript that has been accepted for publication. As a service to our customers we are providing this early version of the manuscript. The manuscript will undergo copyediting, typesetting, and review of the resulting proof before it is published in its final form. Please note that during the production process errors may be discovered which could affect the content, and all legal disclaimers that apply to the journal pertain. 


\section{Title}

Electroneutral polymersomes for combined cancer chemotherapy

\section{Authors}

Aibani, Noorjahana ${ }^{a}$,Nesbitt, Heathera, Marino, Nino ${ }^{a}$, Jurek, Joanna ${ }^{a}$, O’Neill, Caolina, Martin, Chloe $^{a}$, Di Bari, Ivanab ${ }^{b}$ Sheng, Yingjie ${ }^{a}$, Logan, Kierana, Hawthorne, Susan ${ }^{a}$, McHale, Anthony ${ }^{a}$, Callan, John Fa. and Callan, Bridgeen*a.

${ }^{*}$ Corresponding Author

a. School of Pharmacy and Pharmaceutical Sciences, Ulster University, Coleraine, BT52 1SA, Northern Ireland, United Kingdom

b. Department of chemical sciences, University of Catania, Piazza Università, 2, 95124 Catania CT, Italy

\section{Abstract}

Combination cancer chemotherapy provides an important treatment tool, both as an adjuvant and neoadjuvant treatment, this shift in focus from mono to combination therapies has led to increased interest in drug delivery systems (DDS). DDSs, such as polymersomes, are capable of encapsulating large amounts of multiple drugs with both hydrophilic and hydrophobic properties simultaneously, as well as offering a mechanism to combat multi drug resistant cancers and poor patient tolerance of the cytotoxic compounds utilised. In this article, we report the formulation and evaluation of a novel electroneutral polymersome capable of high encapsulation efficacies for multiple drugs (Doxorubicin, 5-Fluorouracil and leucovorin). The in-vivo biodistribution of the polymersome were established and they were found to accumulate largely in tumour tissue. Polymersome encapsulating the three chemotherapeutic drugs were assessed both in-vitro (BxPC-3 cell line) and in-vivo (following intratumoral and intravenous administration) and compared with the same concentration of the three drugs in solution. We report better efficacy and higher maximum tolerated dose for our combination drug loaded polymersomes in all experiments. Furthermore, intratumorally injected combination drug loaded polymersomes exhibited a $62 \%$ reduction in tumour volume after 13 days when compared with the free combination solutions. A smaller differential of $13 \%$ was observed for when treatment was 
administered intravenously however, importantly less cardiotoxicity was displayed from the polymersomal DDS. In this study, expression of a number of survival-relevant genes in tumours treated with the free chemotherapy combination was compared with expression of those genes in tumours treated with the polymersomes harbouring those drugs and the significance of findings is discussed.

\section{Key words}

Combination chemotherapy, polymersome, pancreatic cancer, nanoparticle, drug delivery system

\subsection{Introduction}

The advantages offered by combining two or more chemotherapies has been recognised and documented from as early as the mid twentieth century [1]. It is now widely accepted that most cancers respond better to combination drug therapy rather than single agent therapy. The accessibility of combination therapies has benefitted from the development of novel formulations such as nanoparticle (NP) drug delivery systems (DDSs). The first commercially available DDS was that of Doxilß in 1996, a liposome containing the chemotherapeutic agent doxorubicin (Dox) [2,3]. Liposomes have been investigated for the delivery of many anticancer agents such as anthracyclines[4-6], platinum compounds[7], antimetabolites[8] and vinca alkaloids[911] aiming to reduce their side effects without affecting their efficacy. Liposomes take advantage of the enhanced permeability and retention (EPR) effect of the tumour vasculature $[12,13]$. Co-encapsulation of multiple drugs in liposomes has shown to provide a synergistic action increasing their efficacy [14-16]. Although there is much evidence to suggest that liposomes have had a significant impact on existing chemotherapeutic treatments, their drawbacks include low stability and shelf life and diffusion of the drug across the liposomal membrane with time [17]. The limitations of liposomal delivery systems have led to a shift in focus towards more stable alternatives. Discher et al. [18] demonstrated in the late 1990s, the ability of diblock copolymers to assemble into bilayer vesicles termed polymersomes [18,19]. Polymersomes provide an alternative DDS by combining the advantages of bilayer forming liposomes with enhanced stability and shelf life [20,21]. The polymer backbone can be designed to include desirable properties such as biodegradability 
and biocompatibility $[22,23]$. The large molecular weights of polymers used for these structures can significantly improve their membrane properties such as permeability, thickness and robustness [24]. Similar to liposomes, polymersomes have the ability to encapsulate both hydrophilic and hydrophobic compounds, however owing to the larger size of the hydrophilic cores [25] and thicker hydrophobic bilayer [26], the amount of encapsulated drug is increased. Recently there have been some interesting examples of polymersomes encapsulating multiple anticancer drugs [27-29]. Dox and paclitaxel loaded polymersomes have shown enhanced anticancer activity against head and neck squamous cancer cells [30] whereas siRNA co-encapsulated with Dox in block copolymer polymersomes in human gastric cancer cell lines has shown increased efficacy at lower doses [31]. There are further examples of combination anticancer therapy using 5-Fluorouracil (5-FU) and Dox loaded in NPs such as dendritic nanomicelles [32], polymer drug conjugated NPs [33] and nanocomplexes [34] all displaying a synergistic action against different types of cancer [35]. Thus, NP DDSs are proving to be a valuable tool for the co-delivery of multi drugs, they are not only effective in treating resistant and recurrent tumours but also have the potential to reduce the time restraints of current combination therapies which are often delivered over a number of consecutive days.

In this manuscript, we describe the simultaneous encapsulation of three anticancer agents, Dox, 5-FU and leucovorin (LV), into a random copolymer polymersome. We report excellent encapsulation efficiencies with both single and multiple occupancy within the polymersomes with the hydrodynamic radius suitable for endocytosis. The in-vitro analysis suggests that the polymersome formulation significantly enhances the efficacy observed with the free drug combination therapy. We describe, for the first time, the biodistribution of this particular DDS in-vivo using fluorescence imaging to show enhanced tumour accumulation. The therapeutic efficacy of the loaded polymersomes was examined using ectopic pancreatic BxPC-3 tumours in mice after both intratumoral and intravenous injection where we report a reduction in tumour growth when compared with treatments using the free solutions. Finally, the treated tumours were analysed for the expression of forty relevant genes. Treatment with the combination drug loaded polymersomes caused a greater reduction in pro- survival gene expression in lesions when compared with expression of those genes following 
treatment with the free drug to combination and the implications of these findings are discussed

\subsection{Materials and Methods}

\section{Materials}

DOX-HCl, 5-FU, LV calcium, indocyanine green (ICG), dialysis membrane (MWCO 12-14kDa), PBS tablets $\mathrm{pH} 7.2$ and chloroform were obtained from Sigma-Aldrich, UK. RPMI 1640, FBS, pen/strep were sourced from Thermofisher Scientific, UK. Matrigel® basement matrix was acquired from Corning Inc.

\subsection{Preparation and characterisation of polymersomes}

Polymersomes were prepared from a previously described random co-polymer [36] containing polyethylene glycol (PEG, Mn 500Da), cholesteryl and a decyl chain in a $73: 12: 15 \% \mathrm{w} / \mathrm{w}$ ratio. Synthesis of the polymer is well documented with characterisation carried out using GPC (Agilent MDS-THF, data collected by Agilent GPC/SEC Software Version 1.2.3182.29519). Formulation was achieved using the reverse phase evaporation method; $0.5 \mathrm{~mL}$ polymer in chloroform $\left(5 \mathrm{mg} \mathrm{mL}^{-1}\right)$ was evaporated to dryness under reduced pressure in a round bottom flask to form a thin film. Depending on the application an appropriate volume and concentrations of Dox, 5-FU and LV were added on top of the film and again evaporated to dryness under the same conditions. $1 \mathrm{~mL}$ Chloroform was added to the round bottom flask and sonicated for 15 minutes using a Branson 3510 bath sonicator (230V) at room temperature, after which $0.5 \mathrm{~mL}$ of the polymer in PBS $\left(5 \mathrm{mg} \mathrm{mL}^{-1}\right)$ and $0.5 \mathrm{~mL}$ PBS were added and the resulting mixture sonicated for a further 30 minutes forming an emulsion. The chloroform layer was then under reduced pressure at $45^{\circ} \mathrm{C}$. The resulting suspension was freeze dried and resuspended as per requirement. Particle size and zeta potential of polymersomes were determined using Malvern Nano-ZS Zetasizer without the use of any size extrusion techniques. SEM images were carried out by applying a small amount of the polymersome onto an aluminium stub. The sample was then lyophilised overnight before being sputter coated with gold and palladium. The images were recorded using a FEI Quanta SEM under a high vacuum in secondary electron mode. 


\subsection{Encapsulation efficiency and release studies of combination drugs}

Encapsulation efficiency of the polymersomes were evaluated by centrifugal filtration using a dialysis membrane and centrifuging the polymersomes at $4^{\circ} \mathrm{C}$ at $3000 \mathrm{rcf}$ for 2 hours. The polymersomes were prepared as described in section 2.1 , following the creation of a thin polymer film, $100 \mu \mathrm{L}$ Dox (0.116 mg mL $\left.\mathrm{mL}^{-1} \mathrm{PBS}\right), 100 \mu \mathrm{L} 5$-FU (5.2 mgs $\mathrm{mL}^{-1}$ PBS) and $100 \mu \mathrm{L}$ LV (25.6 mgs $\mathrm{mL}^{-1}$ PBS) was added and the solution evaporated to dryness with the chloroform added as above for the combination solutions within the polymersome. The freeze dried sample was reconstituted in $1 \mathrm{~mL}$ PBS (containing $5 \mathrm{mg} \mathrm{mL}^{-1}$ polymer, $11.6 \mu \mathrm{g} \mathrm{mL}^{-1}$ Dox, $0.52 \mathrm{mg} \mathrm{mL}^{-1} 5$-FU and 2.56 $\mathrm{mg} \mathrm{mL}^{-1} \mathrm{LV}$ ), the individual polymersomal formulations were prepared to contain an identical amount of one component (only one from: $11.6 \mu \mathrm{gL}^{-1} \mathrm{Dox}, 0.52 \mathrm{mg} \mathrm{mL}^{-1} 5$ FU or $2.56 \mathrm{mg} \mathrm{mL}^{-1} \mathrm{LV}$ ) alongside $5 \mathrm{mg} \mathrm{mL}^{-1}$ polymer. $0.5 \mathrm{~mL}$ of each of the polymersome suspensions were added to a semipermeable membrane (MWCO 12$14 \mathrm{kDa})$, secured at both ends and suspended within a centrifuge tube before centrifugation. The resultant filtrate was collected and analysed for unencapsulated drug. Dox was analysed by fluorescence spectroscopy at Ex 485nm/Em 580nm (y = 91.324x, $\left.R^{2}=0.9881\right), 5-F U$ and LV by UV spectroscopy at absorbance maximum $265 \mathrm{~nm}\left(\mathrm{y}=0.0581 \mathrm{x}, \mathrm{R}^{2}=0.9992\right)$ and $285 \mathrm{~nm}\left(\mathrm{y}=0.0543 \mathrm{x}, \mathrm{R}^{2}=0.9998\right)$ respectively. In vitro release studies of polymersomes were conducted after removing the unencapsulated drug/s and keeping the polymersomes in the sealed dialysis membrane. The sealed semi permeable membrane was stirred in $10 \mathrm{~mL}$ PBS maintained at $37^{\circ} \mathrm{C}$, samples were removed at fixed intervals of time and analysed for individual drug concentration, the same volume of PBS was replaced after each removal to maintain sink conditions.

\subsection{In-vitro study to establish efficacy}

BxPC-3 cells were cultured in RPMI 1640 medium supplemented with $10 \%$ FBS and $1 \%$ pen/strep. $100 \mu \mathrm{l}, 1 \times 10^{5}$ cells $\mathrm{mL}^{-1}$ were seeded into each well on 96 well plates and allowed to adhere overnight. Polymersome solutions were prepared as described for the encapsulation efficiency and release studies, and sterile filtered with a $0.45 \mu \mathrm{m}$ Millex MCE syringe filter. $100 \mu$ of either free solution of individual drugs at identical concentrations, combination free solutions or combination drugs encapsulated in polymersomes were applied to cells generating a 1:1 dilution of test solution with the 
cell media, giving final cell concentrations of; $5.8 \mu \mathrm{g} \mathrm{mL}^{-1}$ Dox, $0.26 \mathrm{mg} \mathrm{mL}^{-1} 5$-FU or $1.28 \mathrm{mg} \mathrm{mL}^{-1} \mathrm{LV}$ and $2.5 \mathrm{mg} \mathrm{mL}^{-1}$ polymer. The cells were then incubated at $37^{\circ} \mathrm{C}$ $\left(20 \% \mathrm{O}_{2} 5 \% \mathrm{CO}_{2}\right)$ for $22 \mathrm{hrs}$. An MTT assay was then performed by incubating each well with $20 \mu \mathrm{l}$ of MTT solution (5mg/ml in PBS) and $100 \mu \mathrm{l}$ of fresh medium for 3 hours and reading the absorbance in DMSO at 570nm using a Fluostar Omega microplate reader.

\subsection{In-vivo biodistribution assay of polymersomes}

In these studies, all animals were treated humanely and in accordance with licenced procedures under the UK Animals (Scientific Procedures) Act, 1986. Animals were anaesthetised using $150 \mu \mathrm{l}$ intraperitoneal injection of water for injection: hypnorm: hypnovel (2:1:1) (VetaPharma Ltd., U.K.). 50 $\mu$ l polymersomes $\left(5 \mathrm{mg} \mathrm{mL}^{-1}\right)$ loaded with $0.2 \mathrm{mg} \mathrm{mL}^{-1}$ ICG were prepared as previously described with $100 \mu \mathrm{L}$ of $2 \mathrm{mg} \mathrm{mL}^{-1} \mathrm{ICG}$ replacing the Dox/5-FU/LV and sterile filtered with a $0.45 \mu \mathrm{m}$ Millex MCE syringe filter before being injected into the tail vein of mice previously implanted with ectopic BxPC3 tumours as described in section 2.5. Following administration, animals were placed in Xenogen IVIS $\AA$ Lumina imaging system chamber maintained at $37^{\circ} \mathrm{C}$ equipped with an ICG filter set (Ex 705-780 nm; Em 810-885 nm). Images were recorded at regular intervals up to 22 hours to observe the in-vivo biodistribution of the DDS in real time. After 22 hours, the mice were sacrificed and their organs and tumours were harvested and imaged for the presence of ICG fluorescence. All data were analysed using Living Image ${ }^{\circledR}$ software version 2.60 and reported relative to the background emission.

\subsection{Treatment efficacy after Intratumoral and intraveneous injection}

BxPC- 3 cells $\left(5 \times 10^{6}\right.$ cells per mouse) were resuspended in RPMI 1640 medium and Matrigel $\AA$ in $1: 1$ ratio and implanted subcutaneously into the rear dorsum of NODSCID mice (NOD.CB17-Prkdcscid/NCrHsd). Tumour formation occurred approximately 2 weeks after tumour cell implantation, tumours were measured via calipers and tumour volume calculated using the formula $(\mathrm{LxW} \times \mathrm{H}) / 2)$. Once tumours reached $200-250 \mathrm{~mm}^{3}$ animals were grouped and treatment commenced.

After the ectopic tumours reached the desired volume, the mice were randomly segregated into 6 groups of 3 or 4 mice in each group. Prior to treatment animals receiving the intratumoral injections were anaesthetised using intraperitoneal 
administration of Hypnorm/Hypnovel. Treatment groups consisting of; control untreated animals; those treated with empty polymersomes (intratumoral), combination solution (intratumoral), combination loaded polymersomes (intratumoral), combination solution (I36V) and combination loaded polymersomes (IV). The concentration of 5-FU and LV to be added was calculated using the therapeutic range in humans (450-600 $\mathrm{mg} / \mathrm{m}^{2}$ and $20-100 \mathrm{mg} / \mathrm{m}^{2}$ respectively)(Table S1). Due to the extremely recalcitrant nature of pancreatic cancer the concentration for Dox was higher than the therapeutic range (generally $40-75 \mathrm{mg} / \mathrm{m}^{2}$ ) but in line with similar studies [37]. Calculations were based on an average surface area of an adult human body being $1.73 \mathrm{~m}^{2}$ with an average weight of $60 \mathrm{~kg}$. Calculations were originally based on an estimated average mouse weight of $20 \mathrm{~g}$ and adjusted to allow for the actual average weight of the mice used of $23.5 \mathrm{~g}$. Solutions of $100 \mu \mathrm{l}$ Dox ( $5 \mathrm{mg} \mathrm{mL}^{-1}$ in water), $250 \mu \mathrm{l} 5$-FU (8 $\mathrm{mg} \mathrm{mL}^{-1}$ in water) and $50 \mu \mathrm{LV}\left(5 \mathrm{mg} \mathrm{mL}^{-1}\right.$ in water) were added to the polymer thin film and evaporated as before. The final freeze dried sample was resuspended in $50 \mu \mathrm{L}$ PBS to generate the required concentrations and sterile filtered with a $0.45 \mu \mathrm{m}$ Millex MCE syringe filter. Polymersomes (polymer $(42.5 \mathrm{mg} / \mathrm{kg}$ ) loaded with Dox $(4.3 \mathrm{mg} / \mathrm{kg}), 5-\mathrm{FU}(17 \mathrm{mg} / \mathrm{kg})$ and LV $(2.1 \mathrm{mg} / \mathrm{kg}))$ were injected either intratumorally or intravenously at $100 \mu$ volume on Day 0 and Day 5 of treatment in mice according to their respective groups whereas the untreated group received no treatment. Tumour volume and body weight was measured every day for 13 days after intratumoral injection and 7 days after intravenous injection. On completion of data collection, mice were sacrificed and their tumours and hearts were harvested. Hearts were weighted and stored in formalin free tissue fixative for further observations. Tumour doubling time was calculated using an online calculator [38].

\subsection{Assessment of Cardiotoxicity after intravenous treatment}

Hearts from the above experiment were weighted and histologically stained in order to assess cardiotoxicity. Fixed hearts were dehydrated in a series of ascending concentrations of methanol; 50\%, 70\%, $90 \%$ and 100\% (one hour each).Tissue samples were washed twice in $100 \%$ methanol (one hour each). Samples were cleared with a xylene substitute (Sigma, UK) for 4 hours and embedded in molten paraffin wax (Sigma, UK). A microtome (RM2135; Leica, Germany) was used to section heart tissue to $5 \mu \mathrm{m}$ thickness. Sections were placed on glass slides and dried overnight before being hematoxylin-eosin stained (H \& E). 


\subsection{Gene expression analysis on xenografts treated with combination polymersomes}

To establish the effect of drug loaded polymersomes on the expression of specific genes involved in the development and progression of pancreatic cancer. 40 candidate genes involved in pancreatic cancer progression were analysed with 28 of these having a $\mathrm{Cp}$ value of less than 40 (BID, BAX, BCL2, BCL2L1, BAD, BIK, EPCAM, MET, ALDH1A1, VEGFA, VEGFC, NME1, CA9, CTGF, RUNX2, CNDP2, TFE3, ARL8B, CLN3, TOP2A, HIF1A, ABCC1, AGA, CLCN7, CASP3, IL8, NANOG and SOX2). Tumours in mice from untreated, combination solution (IV) and combination polymersomes (IV) were excised at the experimental endpoint (Day 7). Tumours were snap-frozen using liquid nitrogen and RNA was extracted using Trizol reagent (Life Technologies) in accordance with the manufacturer's instructions [39]. $1.25 \mu \mathrm{g}$ of RNA per tumour was reverse transcribed using the First Strand cDNA synthesis kit (Roche) in accordance with the manufacturer's instructions [40] and the cDNA from the tumours in each group were pooled. Samples were analysed in duplicate on Roche RealTime Ready custom 96 well gene panels (Roche) containing the relevant target genes. The results were normalised to a reference gene set (Beta actin, 18s ribosomal RNA and GAPDH) and the fold changes in gene expression in tumours treated with combination solutions and with combination polymersomes were compared to untreated expression levels; genes considered up-regulated $(\geq 2)$ or down-regulated $(\leq 0.5)$ and those which satisfied a $p$ value $<0.05$ (to the left of the vertical green line, Figure 13A) were deemed statistically significant (student $t$-test). Results shown are mean \pm SE of $\geq 3$ pooled tumours analysed in duplicate.

\subsection{Statistical analysis}

All data are reported as $n=3$ unless otherwise stated. Error bars indicate \pm SEM. Statistical significance of groups was determined using Unpaired Student's $t$ test in Graphpad Prism Version 5.01.

\subsection{Results and Discussion}

\subsection{Characterisation and evaluation of polymersomes}


The amphiphilic random copolymer used for the preparation of polymersomes was composed of three components, two hydrophobic components comprising of a decyl chain, and cholesterol as well as a hydrophilic component, poly (ethylene) glycol (PEG) with an average molecular weight of 500Da. Polymerisation was achieved by free radical polymerisation using AICN as the initiator. The mass of the polymer was determined by GPC and found to have a Mn of 3.2KDa with a PDI of 3.6. As the polymer formed was a random co-polymer, the exact positioning of each monomer relative to each other is not guaranteed. However, on formation of the polymersome, due to the amphiphilic nature of the components the PEG 500 forms the hydrophilic inner core and outer corona of the polymersome whereas the cholesterol and decyl chain form the hydrophobic bilayer of the polymersomes as depicted in Figure $1 \mathrm{~A}$.

Multiple drug loaded polymersomes were prepared by the reverse phase evaporation method as described above in section 2.1 with each of the three drugs encapsulated into the aqueous core. The hydrodynamic radius, PDI, zeta potential and encapsulation efficiencies of the polymersome formulations can see seen in Table 1. Figure 1B displays the SEM images of the Dox loaded polymersomes, the spherical morphology is apparent with the NP's of a similar size range. The size of all polymersomes was found to be less than $300 \mathrm{~nm}$ with a PDI of less than 0.5 and low zeta potential, all of which are expected for electroneutral NPs of this type. The simultaneous encapsulation of 5-FU, Dox and LV eliminates their solution incompatibilities and allows their simultaneous administration with enhanced therapeutic effect. The encapsulation efficiency of all the compounds was greater than $70 \%$ (Table 1) and in agreement with similar studies reported in the literature $[41,42]$.

In-vitro release studies indicate that polymersomes demonstrate a burst effect followed by a fast release of drugs (Figure 2) with more than $65 \%$ of 5 -FU released within 8 hours, whereas just over $40 \%$ for Dox and $30 \%$ LV was released after 8 hours following the initiation of the study. Almost all of 5-FU was released after 24 hours however, release of Dox and LV remained constant. Hence, even though the release of Dox and LV was fast initially, it remained steady to roughly less than $50 \%$ over 24 hours. It was concluded that the amphiphilic copolymer polymersomes were electroneutral, of appropriate size within the nano range required for endocytosis, with PDI's less than 0.5 indicative of sufficiently monodispersed systems, display good 
encapsulation of multiple drugs and are capable of releasing their encapsulated cargo into the surrounding environment.

\subsection{Cell viability studies}

To evaluate the synergistic action of the combination drugs on the cell viability of BxPC-3 cells, free solutions of 5-FU, LV and Dox were compared to their combination free solution and combination drugs loaded in polymersomes at concentrations $5-\mathrm{FU}$ (0.26 mg mL $\left.\mathrm{mg}^{-1}\right)$, LV (1.28 $\left.\mathrm{mg} \mathrm{mL}^{-1}\right)$ and Dox $\left(5.8 \mu \mathrm{g} \mathrm{mL}^{-1}\right)$ and $2.5 \mathrm{mg} \mathrm{mL}^{-1}$ polymer. As seen in Figure 3 , the viability of individual drug solution treated cells were $91.7 \pm 11.0 \%$ for Dox, $91.3 \pm 8.6 \%$ for $5-F U$ and $107.7 \pm 7.0 \%$ for $L V$ indicating only limited toxicity at the above mentioned concentrations. When the same cells were subjected to the combination solution toxicity was higher with $74.9 \pm 6.6 \%$ viable cells, showing a synergistic action with approx. $25 \%$ cytotoxicity. The toxicity was greatly enhanced when the same concentrations were combined within polymersomes, they displayed $\sim 65 \%$ cell toxicity with only $36.5 \pm 3.6 \%$ viable cells. Furthermore, polymersomes with single/dual occupancy drugs were prepared with identical concentrations and the cell viability established. In each of the polymersomes assessed an enhanced toxicity was observed when compared to non polymersomal solutions (Fig. S1). The highest toxicity was recorded from the $5-\mathrm{FU} / \mathrm{LV}$ combination of $49.5 \%$ which was marginally more toxic than the 5-FU single occupancy polymersome (53\% cell viability). This increased toxicity provided by the polymersome encapsulated drugs could suggest enhanced uptake of the drugs. Since the toxicity of the combined drugs in the polymersomes was greater than that exhibited by the individual components of the formulation, the data suggested that a synergistic effect may be occurring. This could provide significant and unforeseen benefits in using such an approach in cancer therapy. To compliment this research, a further polymersome was prepared to contain a higher (x2) concentration of Dox with all other parameters remaining unchanged. The cell viability study (Fig. S2) shows a less than $20 \%$ cell viability with the combination PS Dox $\times 2$, compared with a $48 \%$ cell viability achieved from the same concentration of free solutions. This data would suggest that a. the loading potential of the PS system has not yet been met and b. the synergistic effect could be optimised further, thus creating a more potent drug cocktail. However, this higher concentration 
of Dox was not used in the in-vivo study as cardiotoxicity was of utmost concern, in particular with the free solution controls.

\subsection{In-vivo biodistribution of polymersomes}

In order to ascertain the behaviour of these polymersomes in-vivo we employed polymersomes loaded with Indocyanine green (ICG). ICG is a near infrared dye, commonly used for in-vivo imaging because of its water solubility, easy loading into NPs, good tissue penetration and reduced light scattering [43,44]. Although the method is semi quantitative, it provides the advantage of being able to monitor the behaviour of the polymersomes in the body in real time. Polymersomes loaded with ICG $(0.2 \mathrm{mg} / \mathrm{mL})$ were injected into the tail vein of mice bearing ectopic BxPC-3 tumour. As seen from 4A, the fluorescence after initial injection shows that polymersomes containing the fluorophore were present in the tumour. The polymersomes in peripheral circulation (as indicated by the signal from the extremities as a surrogate fluorescent signal for circulatory vehicle) slowly started to dissipate with a significant amount retained in the tumour tissue as observed 22 hours following administration. Whilst the initial signal from the tumour may be attributed to both circulating and retained vehicle, a plot of tumour fluorescence expressed relative to peripheral tissue fluorescence (Figure 4B) suggests a 6-fold degree of accumulation of polymersomes in the tumour after 8 hours as compared to systemic circulation. Although the signal disappeared from the peripheral tissues with time, the relative amount in the tumour only decreased slightly after 22 hours post injection. To further confirm the accumulation of polymersomes in tumour tissue and determine their tissue distribution, the mouse was dissected, and individual organs were collected for fluorescence observation. Figure 5 shows the individual excised organs with the fluorescence emission from each organ quantified and compared to a blank. The results suggested that there was a significant degree of polymersome accumulation in the tumour, however a significant amount was also seen in the liver. These data support our suggestion that the fluorescent signal from circulating vehicle was decreasing more rapidly than that in the tumour since the fluorescent signal from more highly perfused organs such as the lung and kidney were lower than the less perfused tumour tissues. Figure 5 (insert) displays the fluorescence emission observed from the faeces of the mouse before and after injection with polymersome containing ICG, 
further confirming excretion through the liver. This suggested biodistribution agrees with previous studies carried out by Photos et al. and Fei Lu et al $[45,46]$. They demonstrated that PEG based polymersomes were mainly eliminated by the liver followed by the spleen with a small amount being eliminated by the kidneys. In addition, the lack of accumulation in the heart was an encouraging indication for the potential use of NPs with cardio toxic compounds such as Dox.

\subsection{In-vivo therapeutic efficacy following Intratumoral injection}

Intratumoral injection has been shown to improve tumour concentrations and tumourorgan ratios of injected drugs [47]. Our rationale for using it here was to preclude any unforeseen pharmacokinetic complications and primarily examine the potential therapeutic efficacy of our preparation. NOD-SCID mice were implanted with BxPC3 tumours and the relevant formulation was administered intratumorally when the tumour size was appropriate. On Day 0 and Day 5 mice were injected with either the combination drug loaded polymersomes (comb PS) or combination of three drugs in free solution (comb soln) and their impact on tumour growth was compared with that in mice injected with blank polymersomes and those that received no treatment. Tumour volume was measured each day until the end of treatment (Day 13).

Throughout the duration of the study, the body weight of the mice was regularly recorded and found to remain steady at $90 \pm 10 \%$ (Figure $6 \mathrm{~A}$ ) indicative of limited toxicity caused by the Intratumoral administration of the chemotherapeutic drugs. The individual growth pattern of the tumours is illustrated in Figure 6B for each group. It was interesting to note that there was a spiked increase in recorded tumour volume 2 days after intratumoral injections for both groups containing the therapeutic agents. The injections were carried out on Days 0 and 5, the increase is then seen in Days 1 and 2 and consecutively on Days 6 and 7 for the combination solutions and the combination drug loaded polymersome groups. The increase in recorded volume for the combination solution treated group is more prominent (30-40\%) than those treated with the combination drug loaded polymersomes (5-10\%). This increase in recorded volume is most likely due to the vesicant nature of the Dox [48] and or the inflammatory nature of 5-FU [49], causing local inflammation of the surrounding tissues at the site of injection. This is further confirmed by the lack of any such increase observed with the free polymersome suspension of identical volume. The reason for the reduced 
immune response observed in the combination drug loaded polymersome may be attributed to the protection offered by the polymersome bilayer inhibiting Dox and, to some extent 5-FU, from causing such an inflammatory immune response. In addition, the particulate nature of NPs allows them to diffuse through the interstitial space and lymphatic vessels of the tumour leading to a more homogeneous distribution throughout the tumour tissue, causing a less pronounced inflammatory effect.

Figure 7 displays a photograph of each group containing both the mouse and the excised tumour. It is evident that the smallest tumour was excised following polymersomal treatment with the combination drugs (comb PS), the next most effective treatment was from the free solutions (comb soln) with both the control and the blank polymersomes displaying the largest tumours after 13 days. Figure $8 \mathrm{~A}$ shows the percentage increase in tumour weight of all the groups at the end of the study. The group treated with blank polymersomes had no effect on the tumour toxicity showing $160.2 \pm 21.6 \%$ increase in tumour weight from the initial and having the same trend as the untreated group whose tumour weight increased by $173.5 \pm 42.0 \%$ after 13 days. It was anticipated that the free drug solutions would provide good reduction in tumour weight since the concentrations of Dox, 5-FU and LV were at therapeutic doses. Indeed, the group treated with the combination solution of free drugs exhibited a significant reduction in tumour growth with an increase of only $59.6 \pm 32.8 \%$ tumour weight from the start of the experiment. However, the group treated with combination drug loaded polymersomes had the maximum cytotoxic effect on the tumour showing a decrease of $2.3 \pm 20.4 \%$ in the tumour weight after 13 days which is significantly better than the same concentration of free drug solution.

Tumour doubling times were calculated to be $10.3 \pm 1.20$ and $10.0 \pm 1.4$ days for the control group and the blank PS, respectively. In contrast, the rate of tumour growth for the combination solutions was calculated to be $18.0 \pm 5.0$ days whereas the combination drug loaded polymersome therapy displayed a tumour doubling time calculated to be almost four times slower than the combination solutions at $67.0 \pm 22.0$ days (Figure 8B).

\subsection{In-vivo toxicity after Intravenous injection}

The observation of enhanced retention of polymersomes in tumour tissue of ICG loaded polymersomes, provided the basis for the exploration of antitumor activity of 
multiple drugs-loaded polymersomes administered by intravenous injection. Again, mice with ectopic BxPC-3 tumours were divided randomly into groups receiving intravenous injection of combination free drugs solution (comb soln) on Day 0 and Day 5 , a group receiving combination drug loaded polymersomes (comb PS) at the same concentration on Day 0 and Day 5 and finally a control group that received no treatment. As with the previous study, the body weights of all mice were recorded on a regular basis and data are shown in Figure 9A. The mice treated with combination free drug solution (comb soln) displayed a decrease in the body weight from the first day of treatment which potentiated after the second treatment and the weight of mice fell to $80.0 \pm 4.01 \%$ from their initial weight indicating accumulated systemic toxicity and leading to the termination of the study on day 7 . The mice were weary, distressed and unable to eat and this further exacerbated weight loss. The mice in the untreated and combination drug loaded polymersomes group (comb PS) were relatively healthy with only a $10 \%$ loss in body weight of the latter towards the end of the experiment. The rapid weight loss of mice treated with combination free drug solution is indicative of acute cardiotoxicity of Dox at the concentration administered in mice. Dox has been reported to exhibit acute cardiomyopathy which is dose dependant leading to congestive heart failure at higher doses [50-52]. Other effects of anticancer drugs such as 5-FU and Dox include nausea, vomiting, poor appetite, alopecia and hematopoietic suppression [53,54]. Although cardiotoxicity of Dox remains the most feared side effect of chemotherapy, the encapsulation of Dox into liposomes and other NPs has helped reduce its cardiotoxicity, the most common example being the marketed pegylated liposomal Dox, Doxil® [55-57]. The encapsulation of the combination drugs into polymersomes at the same concentration produced limited toxic side effects in the mice indicating a higher maximum tolerated dose. Figure 9B displays the \% tumour growth of each group. A steady increase in tumour volume was observed for all three groups throughout the 7 days of treatment, with the tumour volume increasing to $74.8 \% \pm 11.8 \%$ in the control group and an increase of $53.7 \pm 11.2 \%$ in the group treated with the combination free drug. Mice treated with combination drug loaded polymersomes displayed the lowest increase in tumour volume of $40.1 \% \pm 10.8 \%$ from initial volume. Following the premature end of the experiment, all the mice were euthanized, and their tumours and hearts were excised. Figure 10 displays a photograph of one mouse from each group with the corresponding excised tumour. This image reinforces the data from Figure $9 \mathrm{~B}$ and displays the smallest tumour 
excised being that from the combination drug loaded polymersomal treatment group. Although the degree of tumour inhibition afforded in these experiments was not as dramatic as that observed when the combination drug-loaded polymersomes were administered intratumorally, we believe that these data demonstrate significant therapeutic benefit over that observed with the free drug, particularly in terms of reducing adverse effects. It should further be noted that although preliminary in nature, the data trend, in terms of tumour size reduction following intravenous administration certainly indicates therapeutic advantage and we believe that this could be further enhanced by manipulating the dosing regimen.

To further confirm an effect on tumour size reduction using the intravenous route of administration with the polymersome formulation, Figure $11 \mathrm{~A}$ displays the $\%$ increase in tumour weight at the end of 7 days. It was found that the tumour weight of mice in the untreated group increased to $92.3 \pm 17.8 \%$ of the initial weight, whereas those in the combination free drug solution and the combination drug loaded polymersomes treated groups increased by $53.8 \pm 13.0 \%$ and $40.1 \pm 12.5 \%$ respectively. Furthermore, the calculation of tumour doubling time indicates that it would take 10.3 \pm 1.2 days and $14.7 \pm 3.7$ days for the untreated group and combination free drug solution group tumours to double in size. However following treatment with the combination drug loaded polymersome formulation, tumours would take the longer time of $21.3 \pm 7.9$ days to double in size (Figure 11B) again confirming a negative impact on tumour growth by the polymersome formulation.

Further evaluation of systemic cardiotoxicity was carried out by the observation of the reduction in heart weights after the completion of the study (Figure 12). It was found that mice treated with combination free drug solution showed an average heart weight of $88 \pm 2 \mathrm{mg}$ which was lower than those of either the untreated group or the combination drug loaded polymersome treated groups which had heart weights of 120 $\pm 2 \mathrm{mg}$ and $100 \pm 1 \mathrm{mg}$ respectively. Furthermore, $\mathrm{H} \& \mathrm{E}$ staining of hearts revealed an increase in nuclei in tissue from animals treated with the Combo Soln. compared with heart tissue from either those treated with the Combo PS or untreated animals (Figure $12 \mathrm{~B}$ ). This suggested that cellular recruitment may be occurring to address toxic insult caused by the drugs in free solution. This was confirmed by the presence of extensive necrotic regions and evidence of cellular mobilisation in tissue harvested from animals treated with the Combo Soln. (Figure 12C) and a distinct absence of both 
in animals treated with the Combo PS or untreated animal. This again demonstrates the potential benefit offered by the novel polymersome formulation and clearly demonstrates a cardio-protective effect afforded by the approach, presumably because of modifying the bioavailability of the cardiotoxic anthracycline (Dox) in the formulation.

\subsection{The effect of treatment with combination polymersomes on expression of candidate gene in tumours.}

RealTime ready custom plates were used to compare the expression of 40 candidate genes involved in pancreatic cancer progression. BxPC-3 tumours were harvested from control untreated tumours and tumours treated with combination free drug solutions and combination polymersomes on Day 7. Gene expression in treated groups was compared to untreated after data were normalised using a reference gene set (Beta actin, 18s ribosomal RNA and GAPDH). Expression changes for all genes are shown as scatter plots (Figure 13A). Genes were significantly different if they fell to the left of the vertical line and above or below the horizontal lines (student $t$-test). The combination solution scatter plot reveals an alteration in genetic profile compared to untreated, highlighting a significant reduction in 6 pro survival genes and a significant increase in 2 pro survival genes. The combination drug loaded polymersomes scatter plots showed a similar trend to combination free drug solution, 9 pro survival genes were down regulated and 3 pro survival genes were upregulated. However, it is notable that combination drug loaded polymersomes causes the scatter plot genes to shift to the bottom left, therefore causing a greater significant reduction in pro survival genes compared to combination free drug solutions. Figure 13B shows specific genes that are significantly up-regulated or down-regulated in either of the treatment groups compared to untreated (set at $0 \%$ expression). Combination free drug solution and combination drug loaded polymersomes causes a reduction in the majority of genes associated with apoptosis, cancer stem cells, angiogenesis, hypoxia, poor patient survival and autophagy compared to the untreated.

The expression of three pro-apoptotic (BIK, BAX and CASP3) and one anti-apoptotic gene (BCL2) were analysed and it was unexpected that treatment with both the free and polymersome-based treatments led to down-regulation of both the pro-apoptotic 
$\mathrm{BIK}$ and BAX genes and yet the anti-apoptotic BCL2 was also down regulated. Although the inter-relationship between these gene products is complex [58,59], it has been shown that survival of BXPC3 cells can be enhanced by upregulation of BCL2 and down-regulation of BAX [60]. Indeed, resistance to gemcitabine in this cell line has been demonstrated to result from ERK1/2 mediated up-regulation of BCL2 and down-regulation of BAX [60]. The observation that our treatments result in downregulation of both of these genes may be fortuitous and the overall ratio of both may be resulting in a pro-apoptotic effect. The result for significant up-regulation of CASP3 following treatment with the polymersome formulation could confirm this suggestion since it is up-regulated by both intrinsic and extrinsic apoptotic signalling pathways and provides further evidence for the enhanced effects on tumour size/doubling time following treatment with the polymersome formulation.

Hypoxia is very common in pancreatic tumours and is a contributing factor in treatment failure. Hypoxic stress results in the establishment of more resistant tumours cells with an aggressive phenotype [61-64]. Pro-oncogenic RUNX2 gene becomes upregulated under hypoxic stress and is partly responsible for driving tumour progression by targeting genes associated with apoptosis, angiogenesis and metastasis [65-68]. Encouragingly, our combination free drug solution and combination drug loaded polymersome treatment causes a reduction (-78\% and $-99 \%)$ in RUNX2 expression compared to untreated. Furthermore, an elevated anti-angiogenic effect is noted in combination drug loaded polymersome compared to combination free drug solution via a reduction of endothelial cell recruitment and survival via VEGFC and IL-8, therefore preventing tumour vascular support [67]. Cancer stem cells (CSC) are a small population of cells that are involved in tumour initiation, growth, metastasis and resistance to therapy [69-74]. CSC are associated with pancreatic cancer progression, encouragingly, 2 of the CSC associated genes investigated (NANOG and SOX2) showed $\geq 10 \%$ reduction in tumours treated with the combination drug loaded polymersomes when compared with expression of those genes in tumours treated with the combination free drug solution. Our data reveal that one out of two of the autophagy marker genes (CLCN7) was down-regulated in both treatment groups. However, CLN3 was increased by $26 \%$ in combination free drug solution treatment and $233 \%$ in combination drug loaded polymersomal treatment compared to the control [75]. Autophagy is a stress response that can enhance survival of cells that 
have been damaged; this is clearly playing a role after our treatment, providing survival capability for cancer cells. This suggests that targeting autophagy could provide additional therapeutic benefit and enhance overall patient survival. Furthermore, the expression of CNDP2 and CTGF [75,76] in clinical cancer biopsies were associated with poor prognosis, our findings reveal CNDP2 is elevated by both treatments. However, CTGF is increased by $145 \%$ following treatment with the combination free drug solution but interestingly significantly reduced to $-87 \%$ in tumours treated with the combination drug loaded polymersome compared to untreated therefore suggesting better patient outcome. Although the above molecular genetic studies indicate positive attributes in terms of gene expression associated with treatment, particularly following treatment with the polymersome-based formulation, it may be necessary to perform these studies closer to the first treatment since tumours had clearly started to reestablish at the time of harvesting. Nevertheless, in overall terms we believe that, although a more in-depth study will be required to elucidate underlying molecular genetic mechanisms underpinning the mediation of cell death mechanism(s) elicited by the polymersome-based formulation, clear benefit in the current analysis appears to be afforded by the approach.

\subsection{Conclusion}

Combination cancer chemotherapy provides an important treatment tool, both as an adjuvant following the surgical removal of a tumour, and as a neoadjuvant therapy for tumours that are hard to reach and remove surgically. NP DDSs are versatile drug delivery systems capable of encapsulating large amounts of multiple drugs simultaneously, proving ideal for multi drug delivery. In addition, they offer a mechanism to combat multi drug resistant cancers and poor patient tolerance of the cytotoxic compounds utilised. Liposomes are at the forefront of NP therapy for cancer, however the problems associated with them provides the need for exploring other delivery vehicles. In this research work, we have demonstrated the formulation of electroneutral polymersomes with a hydrodynamic radius of $\sim 132 \mathrm{~nm}$ and $\mathrm{PDI}$ of $\sim 0.43$ from an amphiphilic random copolymer. The polymersomes were capable of simultaneously encapsulating three drugs namely 5-FU, Dox and LV within the aqueous core at therapeutic concentrations with an encapsulation efficiency no less 
than $70 \%$ for any of the drugs incorporated. In addition, the release profile for the combined drugs was established, with each component following zero order rate kinetics for drug release within the first two hours. Polymersomes loaded with all three drugs displayed significantly better cell toxicity $(36.5 \%$ cell viability) than their corresponding free drug solutions either independently (no drug generated a less than $90 \%$ cell viability) or given concomitantly ( $75 \%$ cell viability) with good biocompatibility determined from the blank polymersomes. The in-vivo behaviour of the polymersome, in terms of biodistribution, was established and found to accumulate largely in the tumour tissue with up to 6-fold accumulation in the tumour after 8 hours of injection when compared to peripheral tissues. The polymersomes encapsulating the three chemotherapeutic drugs were assessed in-vivo and compared with the same concentration of the three drugs in solution following both intratumoral and intravenous administration. We can report better efficacy and higher maximum tolerated dose for our combination drug loaded polymersomes when compared to the combination drug solutions after both intratumoral and intravenous administration to mice bearing ectopic BxPC3 pancreatic cancer tumours. Intratumorally injected combination drug loaded polymersomes provided a $2 \%$ decrease in tumour volume after 13 days when compared with the combination solutions which yielded a $60 \%$ increase in tumour volume following the completion of the study. A smaller $40 \%$ increase in tumour volume was observed for combination drug loaded polymersomes when given intravenously, however this was an improvement on the $53 \%$ increase displayed by tumours following treatment with the combination free drug solutions at day 7 . The combination solution demonstrated extreme cardiotoxicity and weight loss in treated mice whereas only very limited toxicity was observed for the combination drug loaded polymersome. To further support these findings, the tumours were excised, and genetic profiling carried out. In addition to demonstrating gene expression profiles that were suggestive of treatment induced apoptosis, treatment with the combination drug loaded polymersomes favoured down regulation of genes that would normally drive tumour survival, suggesting decreased angiogenesis, alleviation of hypoxia-induced stress and a reduction in stem cellness. In conclusion, the results described herein using this novel formulation provide significant preclinical evidence to suggest that such formulations could play a significant clinical role in the fight against cancer. They achieve this by enabling the formulation of multiple drugs into a single, easily administered dosage form that could also preclude many of the adverse effects 
associated with conventional combination drug-based approaches. In addition, they have the ability to encapsulate drugs that have both high polarities and well as those that are non-polar, thus ensuring that both drug solubility and cell permeability can be overcome from a drug delivery perspective.

Future work for these NPs will include the optimisation of payloads to ensure that the full potential of these DDSs can be met and improve upon the IV results. In addition, the introduction of drug targeting moieties can be covalently linked to the polymer backbone prior to formulation $[28,46]$ or indeed the incorporation of activating compounds to allow for triggered release [77] further reducing unwanted side effects of these toxic therapies while reducing payload and cost. The future of simultaneous delivery using polymersomes is very promising.

\section{Acknowledgements}

The Ulster University and in particular the Vice Chancellors research Scholarship (VCRS) and the Countess Eleanor peel trust fund (grant number JWP 15/05 81) for their financial support

\section{References}

[1] E. Frei, M. Karon, R.H. Levin, E.J. Freireich, R.J. Taylor, J. Hananian, O. Selawry, J.F. Holland, B. Hoogstraten, I.J. Wolman, E. Abir, A. Sawitsky, S. Lee, S.D. Mills, E.O. Jr Burgert, C.L. Spurr, R.B. Patterson, F.G. Ebaugh, G.W. 3rd James, J. H. Moon. The effectiveness of combinations of antileukemic agents in inducing and maintaining remission in children with acute leukemia. Blood. 26 (1965) 642-56

[2] S. Lopes, C. Giuberti, T. Rocha, D. Ferreira, E. Leite, M. Oliveira, Liposomes as Carriers of Anticancer Drugs, in: L. Rangel (Ed.), Cancer Treatment - Conventional and Innovative Approaches, InTech, 2013, pp. 85-124.

[3] P. Yingchoncharoen, D.S. Kalinowski, D.R. Richardson, Lipid-Based Drug Delivery Systems in Cancer Therapy: What Is Available and What Is Yet to Come, Pharmacol. Rev. 68 (2016) 701-787.

[4] A. Gabizon, A.T. Horowitz, D. Goren, D. Tzemach, F. Mandelbaum-Shavit, M.M. Qazen, S. Zalipsky, Targeting Folate Receptor with Folate Linked to Extremities of 
Poly(ethylene glycol)-Grafted Liposomes: In Vitro Studies, Bioconjugate Chem. 10 (1999) 289-298.

[5] E. Rivera, Liposomal Anthracyclines in Metastatic Breast Cancer: Clinical Update, Oncologist. 8 (2003) 3-9.

[6] S.E. Krown, D.W. Northfelt, D. Osoba, J.S. Stewart, Use of liposomal anthracyclines in Kaposi's sarcoma, Semin. Oncol. 31 (2004) 36-52.

[7] Z. Hang, M. Cooper, Z. Ziora, Platinum-based anticancer drugs encapsulated liposome and polymeric micelle formulation in clinical trials, Biochemical Compounds. 4 (2016) 1-10.

[8] Y. Jin, J. Li, L.F. Rong, X.W. Lu, Y. Huang, S.Y. Xu, Pharmacokinetics and tissue distribution of 5 -fluorouracil encapsulated by galactosylceramide liposomes in mice, Acta Pharmacol. Sin. 26 (2005) 250-256.

[9] I.V. Zhigaltsev, N. Maurer, Q.F. Akhong, R. Leone, E. Leng, J. Wang, S.C. Semple, P.R. Cullis, Liposome-encapsulated vincristine, vinblastine and vinorelbine: a comparative study of drug loading and retention, J. Control. Release. 104 (2005) 103111.

[10] C. Lee, Y. Huang, C. Yang, K. Huang, Drug Delivery Systems and Combination Therapy by Using Vinca Alkaloids, Curr. Top. Med. Chem. 15 (2014) 1491-1500.

[11] R. Hofheinz, S. Gnad-Vogt, U. Beyer, A. Hochhaus, Liposomal encapsulated anticancer drugs, Anticancer Drugs. 16 (2005) 691-707.

[12] X. Wang, Y. Wang, Z. Chen, D. Shin, Advances of Cancer Therapy by Nanotechnology, Cancer Res. Treat. 41 (2009) 1.

[13] J. Huwyler, J. Drewe, S. Krähenbühl, Tumor targeting using liposomal antineoplastic drugs, Int. J. Nanomedicine. 3 (2008) 21-29.

[14] J. Meng, F. Guo, H. Xu, W. Liang, C. Wang, X. Yang, Combination Therapy using Co-encapsulated Resveratrol and Paclitaxel in Liposomes for Drug Resistance Reversal in Breast Cancer Cells in vivo, Sci. Rep. 6 (2016) 22390.

[15] Z. Walls, H. Gong, R. Wilson, Liposomal Coencapsulation of Doxorubicin with Listeriolysin O Increases Potency via Subcellular Targeting, Mol. Pharm. 13 (2016) 1185-1190.

[16] K. Camacho, S. Menegatti, D. Vogus, A. Pusuluri, Z. Fuchs, M. Jarvis, M. Zakrewsky, M. Evans, R. Chen, S. Mitragotri, DAFODIL: A novel liposomeencapsulated synergistic combination of doxorubicin and 5FU for low dose chemotherapy, J. Control. Release. 229 (2016) 154-162. 
[17] U. Massing, S. Fuxius, Liposomal formulations of anticancer drugs: selectivity and effectiveness, Drug Resist. Updat. 3 (2000) 171-177.

[18] D.E. Discher, A. Eisenberg, Polymer vesicles, Science. 297 (2002) 967-973.

[19] B. Discher M, Y. Won, D. Ege S, J. Lee C. M., F. Bates S, D. Discher E, D. Hammer A, Polymersomes: Tough Vesicles Made from Diblock Copolymers, Science. 284 (1999) 1143.

[20] S. Poschenrieder, S. Schiebel, K. Castiglione, Polymersomes for biotechnological applications: Large-scale production of nano-scale vesicles, Eng. Life Sci. 17 (2017) 58-70.

[21] A. Johnston, P. Dalton, T. Newman, Polymersomes, smaller than you think: ferrocene as a TEM probe to determine core structure, J. Nanopart. Res. 12 (2010) 1997-2001.

[22] G. Liu, C. Chen, J. Ji, Biocompatible and biodegradable polymersomes as delivery vehicles in biomedical applications, Soft Matter. 8 (2012) 8811-8821.

[23] R. Rikken, H. Engelkamp, R. Nolte, J. Maan, J. van Hest, D. Wilson, P. Christianen, Shaping polymersomes into predictable morphologies via out-ofequilibrium self-assembly, Nat. Commun. 7 (2016) 12606.

[24] J.F. Le Meins, C. Schatz, S. Lecommandoux, O. Sandre, Hybrid polymer/lipid vesicles: state of the art and future perspectives, Mater. Today. 16 (2013) 397-402.

[25] A. Peyret, E. Ibarboure, N. Pippa, S. Lecommandoux, Liposomes in Polymersomes: Multicompartment System with Temperature-Triggered Release, Langmuir. 33 (2017) 7079-7085.

[26] C. LoPresti, H. Lomas, M. Massignani, T. Smart, G. Battaglia, Polymersomes: nature inspired nanometer sized compartments, J. Mater. Chem. 19 (2009) 35763590.

[27] M. Callari, S. Wong, H. Lu, J. Aldrich-Wright, P. de Souza, M. Stenzel, Drug induced self-assembly of triblock copolymers into polymersomes for the synergistic dual-drug delivery of platinum drugs and paclitaxel, Polym. Chem. 8 (2017) 62896299.

[28] D. Zhu, S. Wu, C. Hu, Z. Chen, H. Wang, F. Fan, Y. Qin, C. Wang, H. Sun, X. Leng, D. Kong, L. Zhang, Folate-targeted polymersomes loaded with both paclitaxel and doxorubicin for the combination chemotherapy of hepatocellular carcinoma, Acta Biomater. 58 (2017) 399-412. 
[29] C. Martin, N. Aibani, J.F. Callan, B. Callan, Recent advances in amphiphilic polymers for simultaneous delivery of hydrophobic and hydrophilic drugs, Ther. Deliv. 7 (2016) 15-31.

[30] H. Colley, V. Hearnden, M. Avila-Olias, D. Cecchin, I. Canton, J. Madsen, S. MacNeil, N. Warren, K. Hu, J. McKeating, S. Armes, C. Murdoch, M. Thornhill, G. Battaglia, Polymersome-Mediated Delivery of Combination Anticancer Therapy to Head and Neck Cancer Cells: 2D and 3D in Vitro Evaluation, Mol. Pharm. 11 (2014) 1176-1188.

[31] H. Kim, E. Kim, Y. An, J. Choi, E. Jang, E. Choi, A. Kukreja, M. Kim, B. Kang, D. Kim, J. Suh, Y. Huh, S. Haam, A Biodegradable Polymersome Containing Bcl-xL siRNA and Doxorubicin as a Dual Delivery Vehicle for a Synergistic Anticancer Effect, Macromol. Biosci. 13 (2013) 745-754.

[32] R. Han, Y. Sun, C. Kang, H. Sun, W. Wei, Amphiphilic dendritic nanomicellemediated co-delivery of 5-fluorouracil and doxorubicin for enhanced therapeutic efficacy, J. Drug Target. 25 (2016) 140-148.

[33] Q. Yang, Y. Yang, L. Li, W. Sun, X. Zhu, Y. Huang, Polymeric Nanomedicine for Tumor-Targeted Combination Therapy to Elicit Synergistic Genotoxicity against Prostate Cancer, ACS Appl. Mater. Interfaces. 7 (2015) 6661-6673.

[34] A. Di Martino, P. Kucharczyk, Z. Capakova, P. Humpolicek, V. Sedlarik, Chitosanbased nanocomplexes for simultaneous loading, burst reduction and controlled release of doxorubicin and 5-fluorouracil, Int. J. Biol. Macromol. 102 (2017) 613-624. [35] F. Ahmed, R. Pakunlu I, A. Brannan, F. Bates, T. Minko, D. Discher E, Biodegradable polymersomes loaded with both paclitaxel and doxorubicin permeate and shrink tumors, inducing apoptosis in proportion to accumulated drug, J. Control. Release. 116 (2006) 150-158.

[36] C. Martin, N. Marino, C. Curran, A.P. McHale, J.F. Callan, B. Callan, Cholesteryl to improve the cellular uptake of polymersomes within HeLa cells, Int. J. Pharm. 511 (2016) 570-578.

[37] K. K. Upadhyay, A. N. Bhatt, A. K. Mishra, B. S. Dwarakanath, S. Jain, C. Schatz, J-F. Le Meins, A. Farooque, G. Chandraiah, A. K. Jain, A. Misra, S. Lecommandoux, The intracellular drug delivery and anti tumor activity of doxorudicin loaded poly $(Y-$ benzyl L-gluatamate)-b-hyaluronan polymersomes, Biomaterials. 31 (2010) 28822892. 
[38] Classifications, online calculators and tables in radiology. http://radclass.mudr.org/content/doubling-time-calculation-growth-rate-lesion-ormass, 2013 (accessed 21 August 2017).

[39] Invitrogen

TRIzol

Reagent

Guide.

https://tools.thermofisher.com/content/sfs/manuals/trizol_reagent.pdf, 2016 (accessed 11 November 2017).

[40] Roche, Transcriptor First Strand cDNA Synthesis Kit http://facstaff.bloomu.edu/gdavis/MoBio/Transcriptor\%20full\%20manual.pdf, 2006 (accessed 11 November 2017).

[41] A. Kalra, R. Campbell, Development of 5-FU and Doxorubicin-Loaded Cationic Liposomes against Human Pancreatic Cancer: Implications for Tumor Vascular Targeting, Pharm. Res. 23 (2006) 2809-2817.

[42] Y. Chao, Y. Liang, G. Fang, H. Haibing He, Q. Yao, H. Xu, Y. Chen, X. Tang, Biodegradable Polymersomes as Nanocarriers for Doxorubicin Hydrochloride: Enhanced Cytotoxicity in MCF-7/ADR Cells and Prolonged Blood Circulation, Pharm. Res. 34 (2017) 610-618.

[43] C. Zheng, M. Zheng, P. Gong, D. Jia, P. Zhang, B. Shi, Z. Sheng, Y. Ma, L. Cai, Indocyanine green-loaded biodegradable tumor targeting nanoprobes for in vitro and in vivo imaging, Biomaterials. 33 (2012) 5603-5609.

[44] Z. Sheng, D. Hu, M. Xue, M. He, P. Gong, L. Cai, Indocyanine Green Nanoparticles for Theranostic Applications, Nano-Micro Lett. 5 (2013) 145-150.

[45] P.J. Photos, L. Bacakova, B. Discher, F.S. Bates, D.E. Discher, Polymer vesicles in vivo: correlations with PEG molecular weight, J. Control. Release. 90 (2003) 323334

[46] F. Lu, Z. Pang, J. Zhao, K. Jin, H. Li, Q. Pang, L. Zhang, Z. Pang, Angiopep-2conjugated poly(ethylene glycol)-co-poly(ع-caprolactone) polymersomes for dualtargeting drug delivery to glioma in rats, Int. J. Nanomed. 12 (2017) 2117-2127.

[47] T. Lammers, P. Peschke, R. Kühnlein, V. Subr, K. Ulbrich, P. Huber, W. Hennink, G. Storm, Effect of Intratumoral Injection on the Biodistribution, the Therapeutic Potential of HPMA Copolymer-Based Drug Delivery Systems, Neoplasia. 8 (2006) 788-795.

[48] H. Cortés-Funes, C. Coronado, Role of anthracyclines in the era of targeted therapy, Cadiovas. Toxicol. 7 (2007) 56-60. 
[49] F. Ghiringhelli, M. Buchard, L. Apetoh. Immune effects of 5-fluorouracil. Ambivalence Matters. Oncoimmunology. 2 (2013) e23138. doi: 10.4161/onci.23139 [50] S. Swain, F. Whaley, M. Ewer, Congestive heart failure in patients treated with doxorubicin, Cancer. 97 (2003) 2869-2879.

[51] M. Volkova, R. Russell, Anthracycline Cardiotoxicity: Prevalence, Pathogenesis and Treatment, Curr. Cardiol. Rev. 7 (2012) 214-220.

[52] A. De Angelis, K. Urbanek, D. Cappetta, E. Piegari, L. Ciuffreda, A. Rivellino, R. Russo, G. Esposito, F. Rossi, L. Berrino, Doxorubicin cardiotoxicity and target cells: a broader perspective, Cardio-Oncology. 2 (2016).

[53] S. Thomas, Z. Grami, S. Mehta, K. Patel, Adverse Effects of 5-fluorouracil: Focus on Rare Side Effects, Cancer Cell Microenviron. 3 (2016) e1266.

[54] Y. Octavia, C. Tocchetti, K. Gabrielson, S. Janssens, H. Crijns, A. Moens, Doxorubicin-induced cardiomyopathy: From molecular mechanisms to therapeutic strategies, J. Mol. Cell. Cardiol. 52 (2012) 1213-1225.

[55] O. Lyass, B. Uziely, R. Ben-Yosef, D. Tzemach, N. Heshing, M. Lotem, G. Brufman, A. Gabizon, Correlation of toxicity with pharmacokinetics of pegylated liposomal doxorubicin (Doxil) in metastatic breast carcinoma, Cancer. 89 (2000) 1037 1047.

[56] S. Rafiyath, M. Rasul, B. Lee, G. Wei, G. Lamba, D. Liu, Comparison of safety and toxicity of liposomal doxorubicin vs. conventional anthracyclines: a meta-analysis, Exp. Hematol. Oncol. 1 (2012) 10.

[57] L. Gonzalez-Fajardo, L. Mahajan, D. Ndaya, D. Hargrove, J. Manautou, B. Liang, M. Chen, R. Kasi, X. Lu, Reduced in vivo toxicity of doxorubicin by encapsulation in cholesterol-containing self-assembled nanoparticles, Pharmacol. Res. 107 (2016) 93101.

[58] B. Antonsson, Bax and other pro-apoptotic Bcl-2 family "killer-proteins" and their victim the mitochondrion, Cell Tissue Res. 306 (2001) 347-361.

[59] A. Samali, J. Cai, B. Zhivotovsky, D.P. Jones, S. Orrenius, Presence of a preapoptotic complex of pro-caspase-3, Hsp60 and Hsp10 in the mitochondrial fraction of jurkat cells, EMBO J. 18 (1999) 2040-2048.

[60] M.Wang, X. Lu, X. Dong, F. Hao, Z. Liu, G. Ni, D. Chen, pERK1/2 silencing sensitizes pancreatic cancer BXPC3 cell to gemcitabine-induced apoptosis via regulation of Bax and Bcl2 expression. 13 (2015) World J Surg Oncol. Online: doi: 10.1186/s12957-015-0451-7. 
[61] N.M. Byrne, H. Nesbitt, L. Ming, S.R. McKeown, J. Worthington, D.J. McKenna, Androgen deprivation in $\mathrm{LNCaP}$ prostate tumour xenografts induces vascular changes and hypoxic stress, resulting in promotion of epithelial-to-mesenchymal transition, $\mathrm{Br}$. J. Cancer. 114 (2016) 659-668.

[62] A.E. Greijer, d.W. van, The role of hypoxia inducible factorÂ 1 (HIF-1) in hypoxia induced apoptosis, J. Clin. Pathol. 57 (2004) 1009-1014.

[63] Z. Li, J.N. Rich, Hypoxia and hypoxia inducible factors in cancer stem cell maintenance, Curr. Top. Microbiol. Immunol. 345 (2010) 21-30.

[64] Y. Tsai, K. Wu, Hypoxia-regulated target genes implicated in tumor metastasis, J. Biomed. Sci. 19 (2012) 102-102.

[65] J. Pratap, A. Javed, L.R. Languino, A.J. van Wijnen, J.L. Stein, G.S. Stein, J.B. Lian, The Runx2 osteogenic transcription factor regulates matrix metalloproteinase 9 in bone metastatic cancer cells and controls cell invasion, Mol. Cell. Biol. 25 (2005) 8581-8591.

[66] G. Browne, H. Nesbitt, L. Ming, G.S. Stein, J.B. Lian, S.R. McKeown, J. Worthington, Bicalutamide-induced hypoxia potentiates RUNX2-mediated Bcl-2 expression resulting in apoptosis resistance, Br. J. Cancer. 107 (2012) 1714-1721.

[67] H. Nesbitt, G. Browne, K.M. O'Donovan, N.M. Byrne, J. Worthington, S.R. McKeown, D.J. McKenna, Nitric Oxide Up-Regulates RUNX2 in LNCaP Prostate Tumours: Implications for Tumour Growth In Vitro and In Vivo, J. Cell. Physiol. 231 (2016) 473-482.

[68] E. Zelzer, D.J. Glotzer, C. Hartmann, D. Thomas, N. Fukai, S. Soker, B.R. Olsen, Tissue specific regulation of VEGF expression during bone development requires Cbfa1/Runx2, Mech. Dev. 106 (2001) 97-106.

[69] Y. Ohara, T. Oda, M. Sugano, S. Hashimoto, T. Enomoto, K. Yamada, Y. Akashi, R. Miyamoto, A. Kobayashi, K. Fukunaga, Y. Morishita, N. Ohkohchi, Histological and prognostic importance of $\mathrm{CD} 44(+) / C D 24(+) / E p C A M(+)$ expression in clinical pancreatic cancer, Cancer. Sci. 104 (2013) 1127-1134.

[70] A. Li, S. Dubey, M.L. Varney, B.J. Dave, R.K. Singh, IL-8 directly enhanced endothelial cell survival, proliferation, and matrix metalloproteinases production and regulated angiogenesis, J. Immunol. 170 (2003) 3369-3376.

[71] Y. Cao, J.A. Espinola, E. Fossale, A.C. Massey, A.M. Cuervo, M.E. MacDonald, S.L. Cotman, Autophagy is disrupted in a knock-in mouse model of juvenile neuronal ceroid lipofuscinosis, J. Biol. Chem. 281 (2006) 20483-20493. 
[72] A. Mohammed, N.B. Janakiram, M. Brewer, R.L. Ritchie, A. Marya, S. Lightfoot, V.E. Steele, C.V. Rao, Antidiabetic Drug Metformin Prevents Progression of Pancreatic Cancer by Targeting in Part Cancer Stem Cells and mTOR Signaling, Transl. Oncol. 6 (2013) 649-659.

[73] S.M. Sureban, R. May, S.A. Lightfoot, A.B. Hoskins, M. Lerner, D.J. Brackett, R.G. Postier, R. Ramanujam, A. Mohammed, C.V. Rao, J.H. Wyche, S. Anant, C.W. Houchen, DCAMKL-1 regulates epithelial-mesenchymal transition in human pancreatic cells through a miR-200a-dependent mechanism, Cancer Res. 71 (2011) 2328-2338.

[74] L. Li, L. Borodyansky, Y. Yang, Genomic instability en route to and from cancer stem cells, Cell. Cycle. 8 (2009) 1000-1002.

[75] C. Xue, Z. Zhang, H. Yu, M. Yu, K. Yuan, T. Yang, M. Miao, H. Shi, Up-regulation of CNDP2 facilitates the proliferation of colon cancer, BMC Gastroenterol. 14 (2014) 96.

[76] C.Y. Chu, C.C. Chang, E. Prakash, M.L. Kuo, Connective tissue growth factor (CTGF) and cancer progression, J. Biomed. Sci. 15 (2008) 675-685.

[77] H-C. Wang, Y. Zhang, C.M. Possanza, S.C. Zimmerman, J. Cheng, J.S. Moore, K. Harris and J.S. Katz, Trigger Chemistries for better industrial formulations, ACS App. Mater. Interfaces 7 (2015) 6369 - 6382.

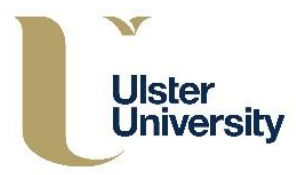

\section{Statement of significance for manuscript entitled "Electroneutral polymersomes for the targeted delivery of three cancer chemotherapy drugs: In-vitro and in-vivo evaluation".}

The shift in focus from mono to combination chemotherapies has led to an increased interest in the role of drug delivery systems (DDS). Liposomes, although commercialized for mono therapy, have lower loading capacities and stability than their polymeric counterpart, polymersomes. Polymersomes are growing in prevalence as their advantageous properties are better understood and exploited. Here we present a novel polymersome for the encapsulation of three anticancer compounds. This is the first time this particular polymersome has been used to encapsulate these three compounds with both an in-vitro and in-vivo evaluation carried out. This work will be of 
interest to those in the field of combination therapy, drug delivery, drug toxicity, multidrug resistance, liposomes, DDS and polymersomes.

\section{Tables}

Table 1. Characterisation and encapsulation efficiency of various polymersomal formulations, both with single occupancy drugs and combination occupancy.

\begin{tabular}{|c|c|c|c|c|c|}
\hline & Blank & DOX only & 5-FU only & LV only & $\begin{array}{l}\text { Combination of } \\
\text { all three }\end{array}$ \\
\hline Size (nm) & $141 \pm 18.2$ & $235.6 \pm 35.5$ & $205 \pm 3.3$ & $175 \pm 38.2$ & $133 \pm 35.5$ \\
\hline PDI & $0.27 \pm 0.06$ & $0.40 \pm 0.01$ & $0.44 \pm 0.02$ & $0.4 \pm 0.05$ & $0.43 \pm 0.14$ \\
\hline Zeta (mV) & $\begin{array}{l}-0.82 \mathrm{mV} \\
\pm 0.2\end{array}$ & $\begin{array}{l}- \\
1.15 \pm 1.11\end{array}$ & $-1.02 \pm 0.93$ & $-1.6 \pm 0.6$ & $-2.79 \pm 1.22$ \\
\hline $\begin{array}{l}\text { Encapsulation } \\
\text { efficiency (\%) }\end{array}$ & N/A & $87.2 \pm 1.7$ & $81.4 \pm 1.6$ & $89.7 \pm 0.5$ & $\begin{array}{ll}\text { Dox } & 81.5 \pm 5.5 \\
\text { 5-FU } & 74.5 \pm \\
20.1 & \\
\text { LV } & 72.1 \pm 0.7\end{array}$ \\
\hline
\end{tabular}



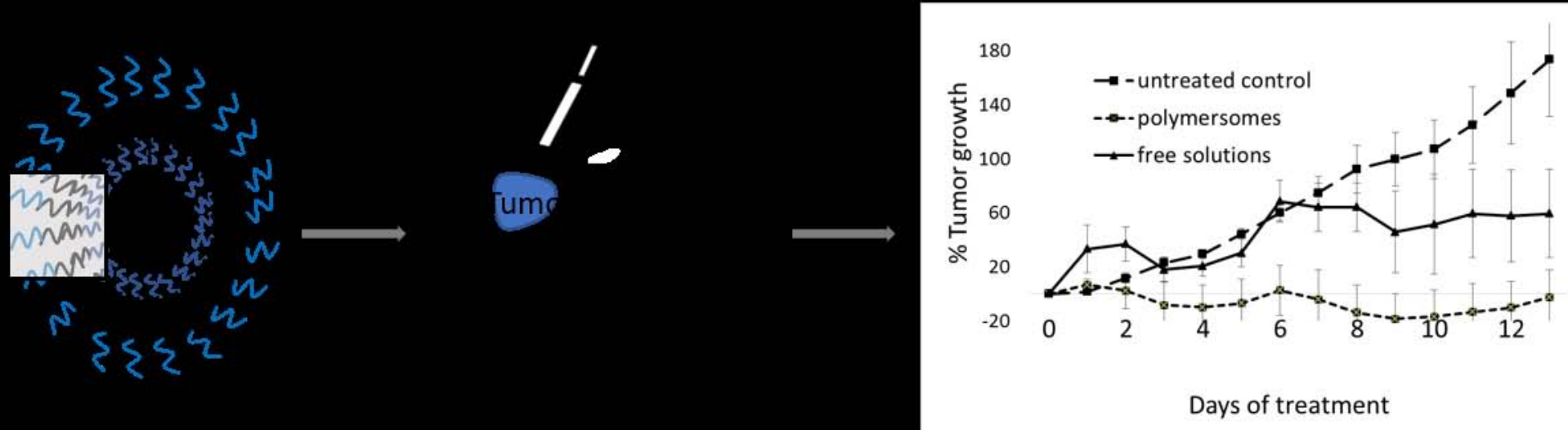
(A)

Combination Solution

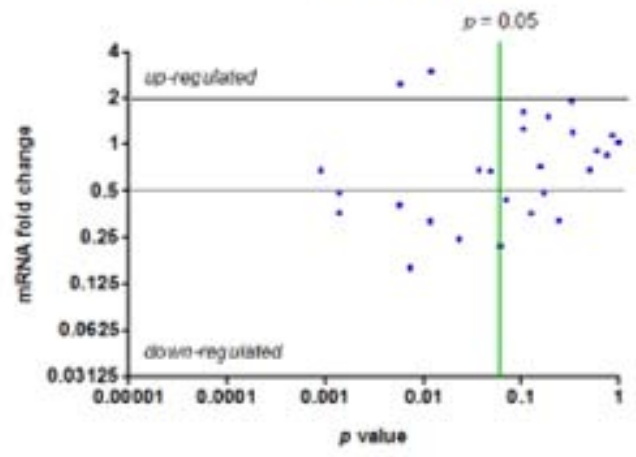

(B)

\section{Combination Polymersomes}

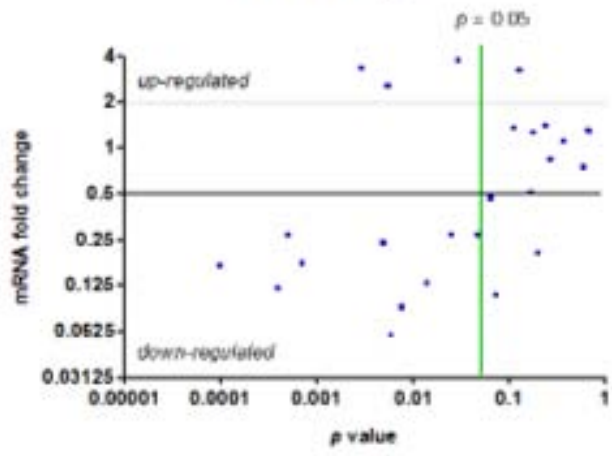

Combination Solution

- Combination Polymersomes

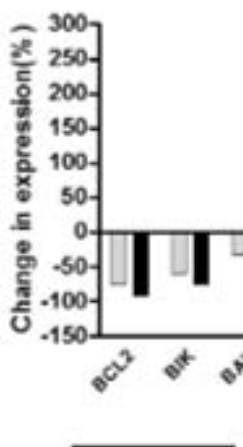

Apoptosis

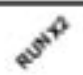

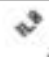
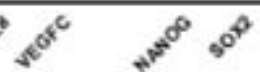

$\theta^{*} \sigma^{*}$

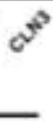

Angiogenesis cscs
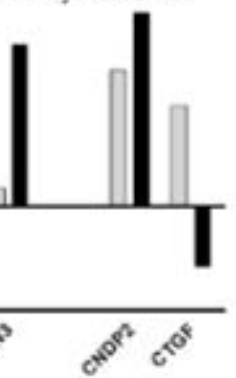

Autophagy
Poor Prognosis 
A

B

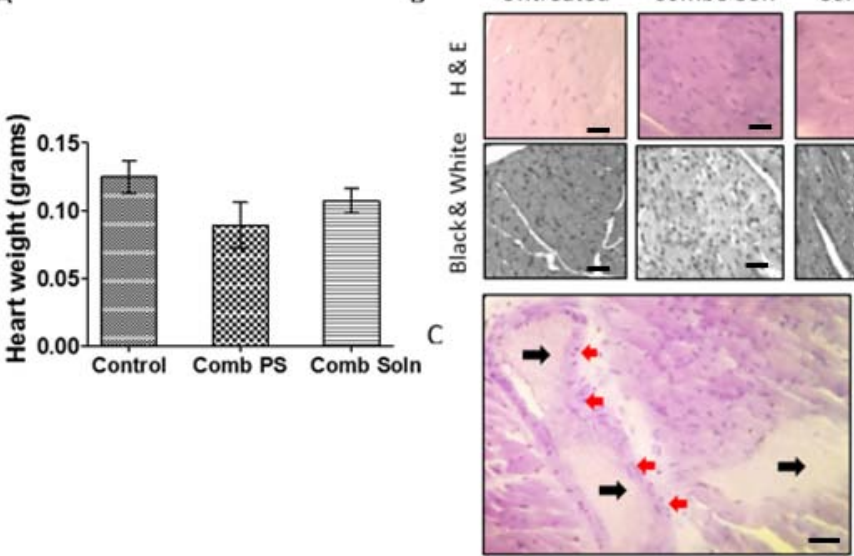

Untreated Combo Son Combo PS

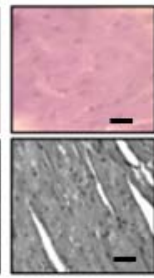

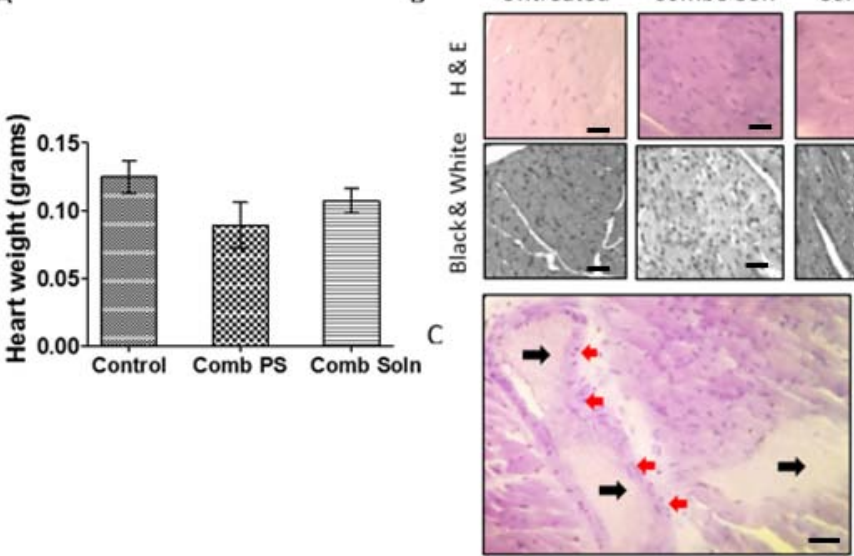

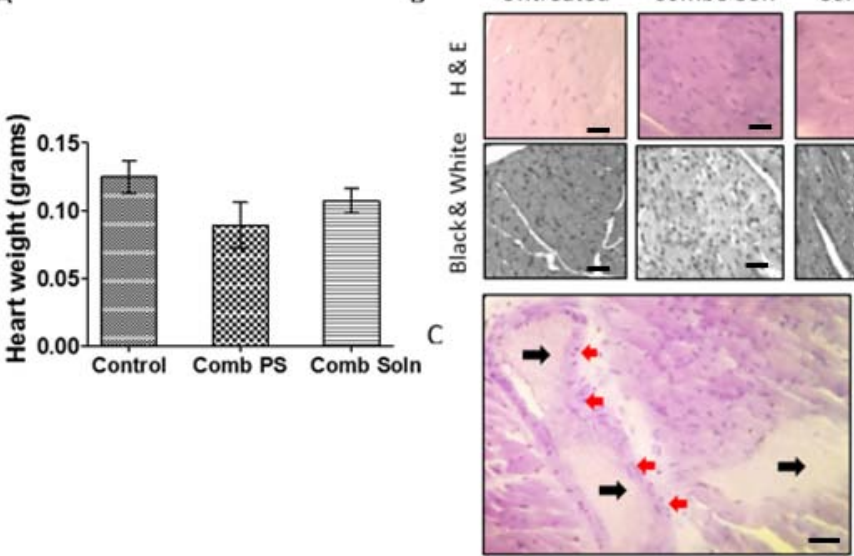



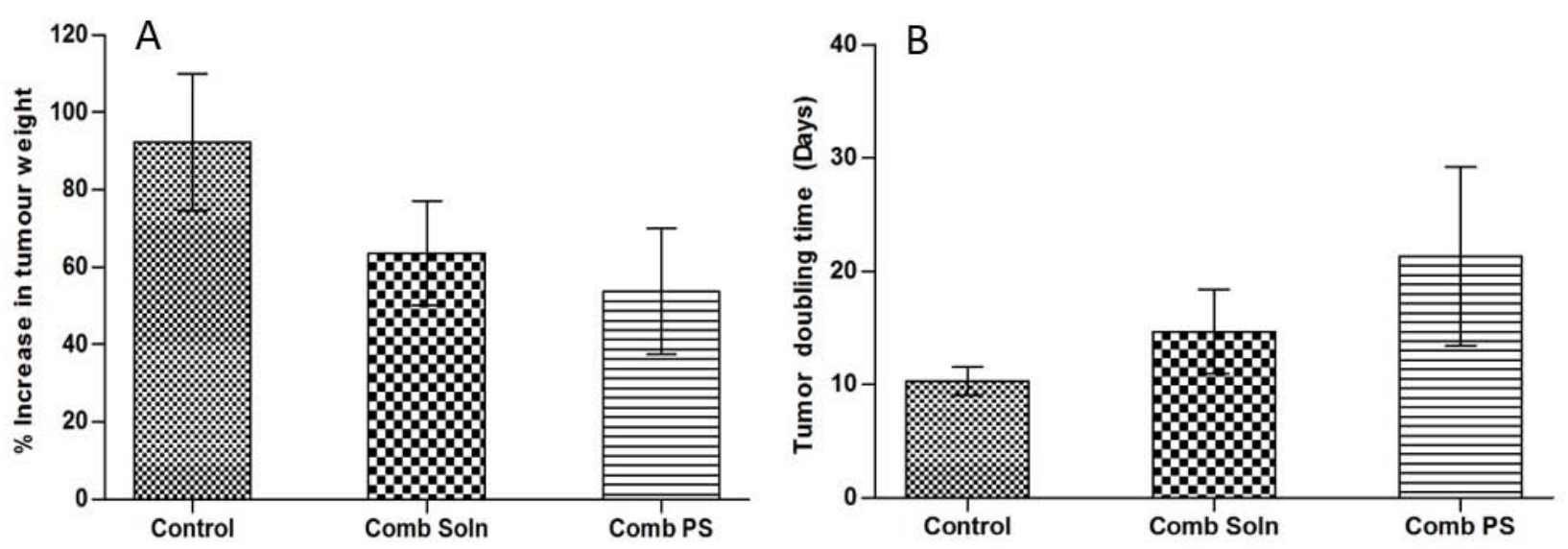


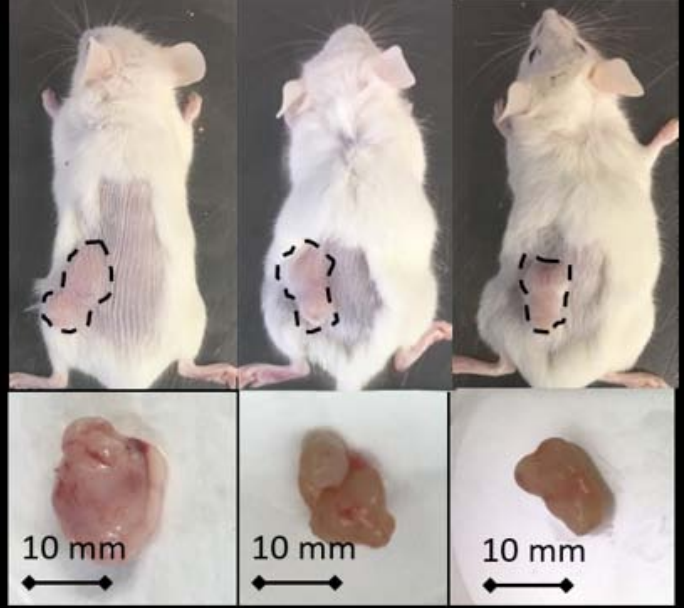



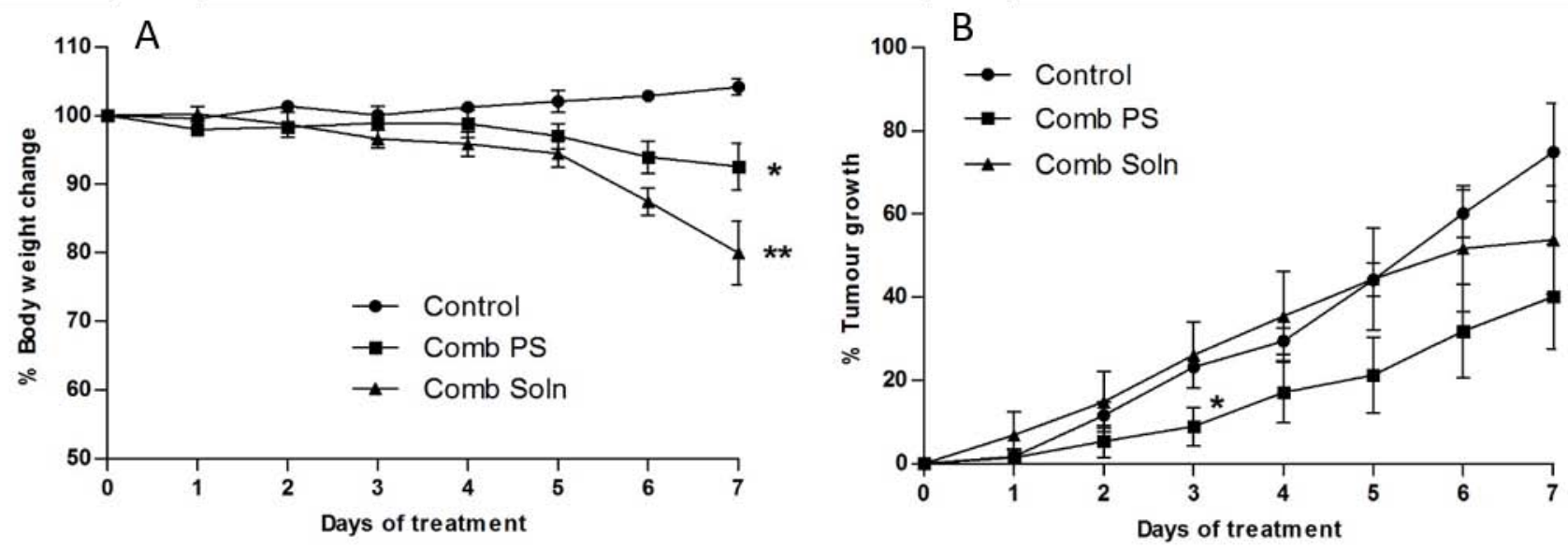


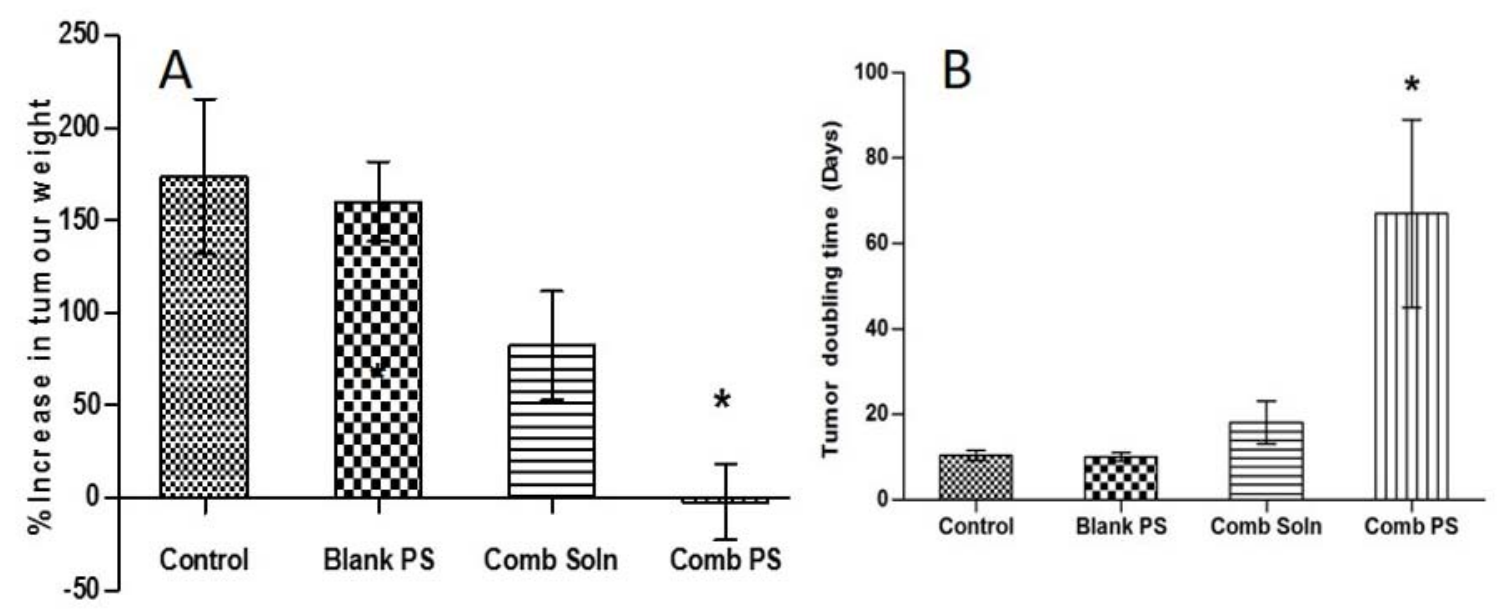




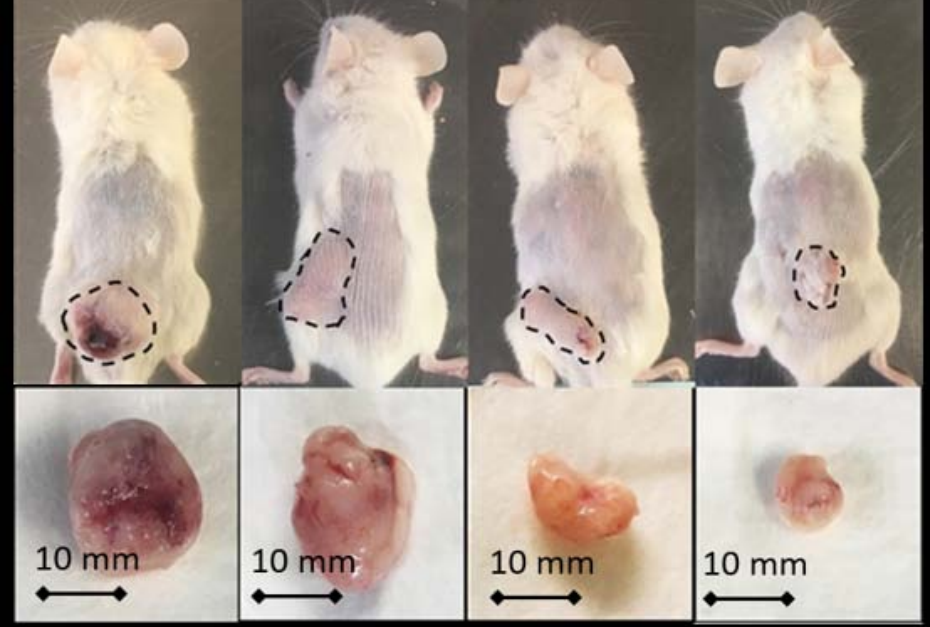



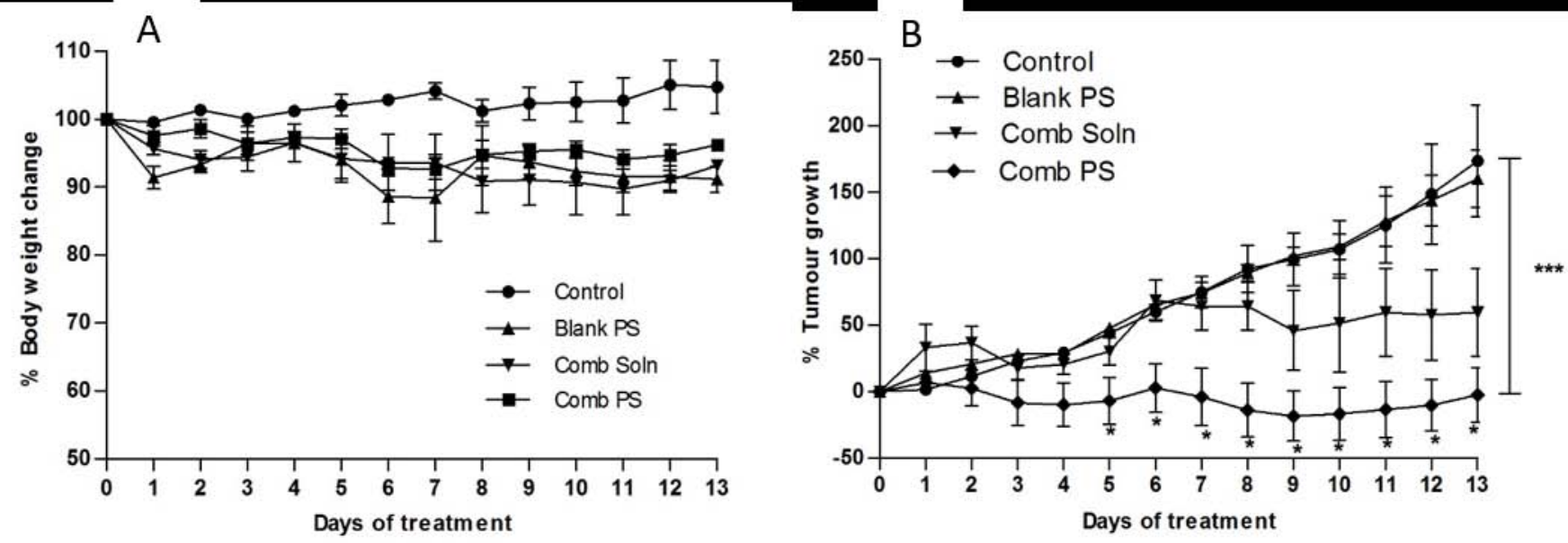


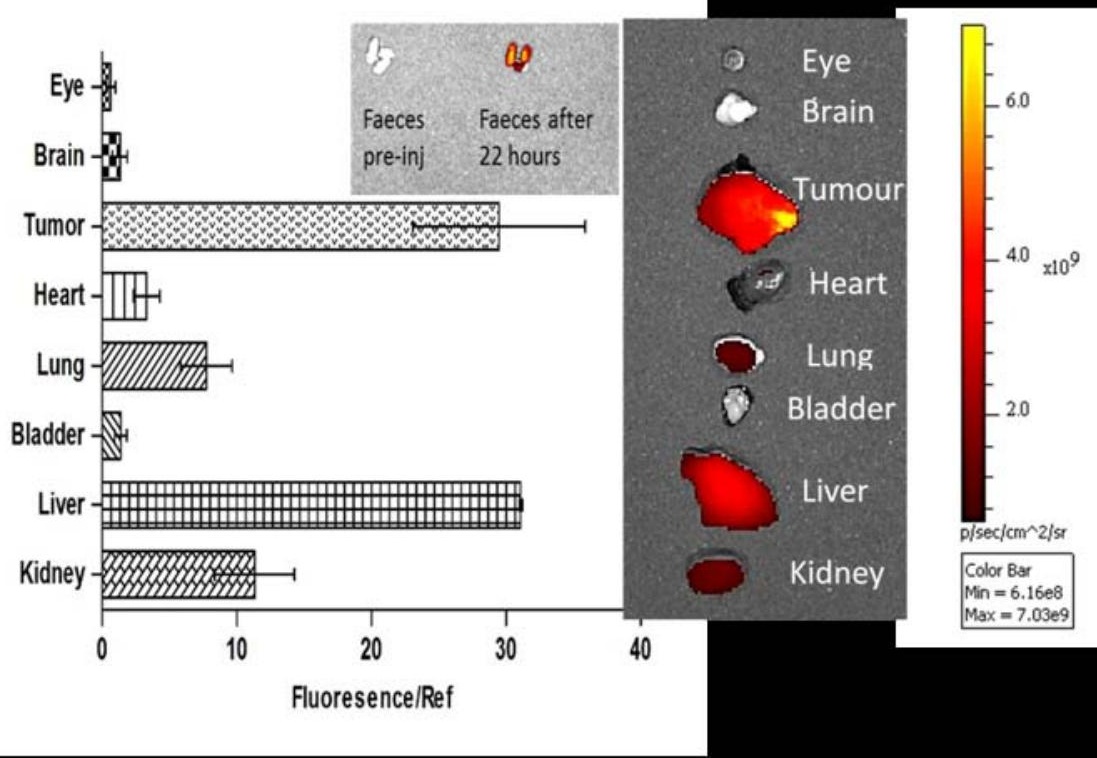




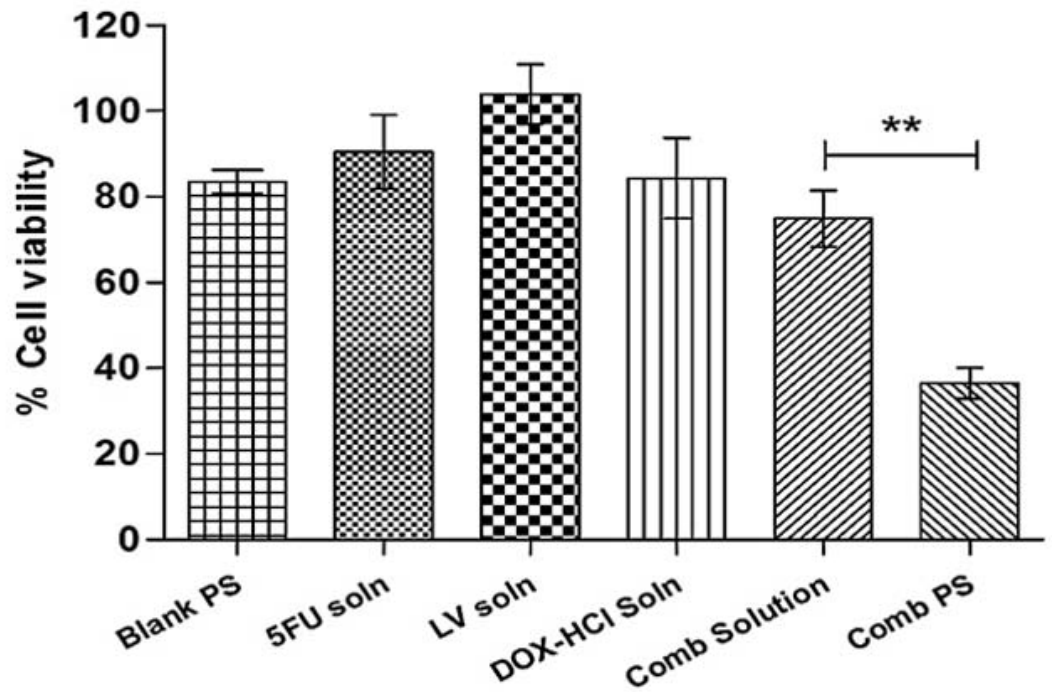




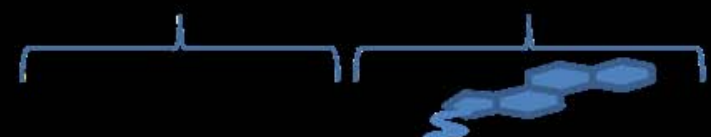

* * : NARNAN
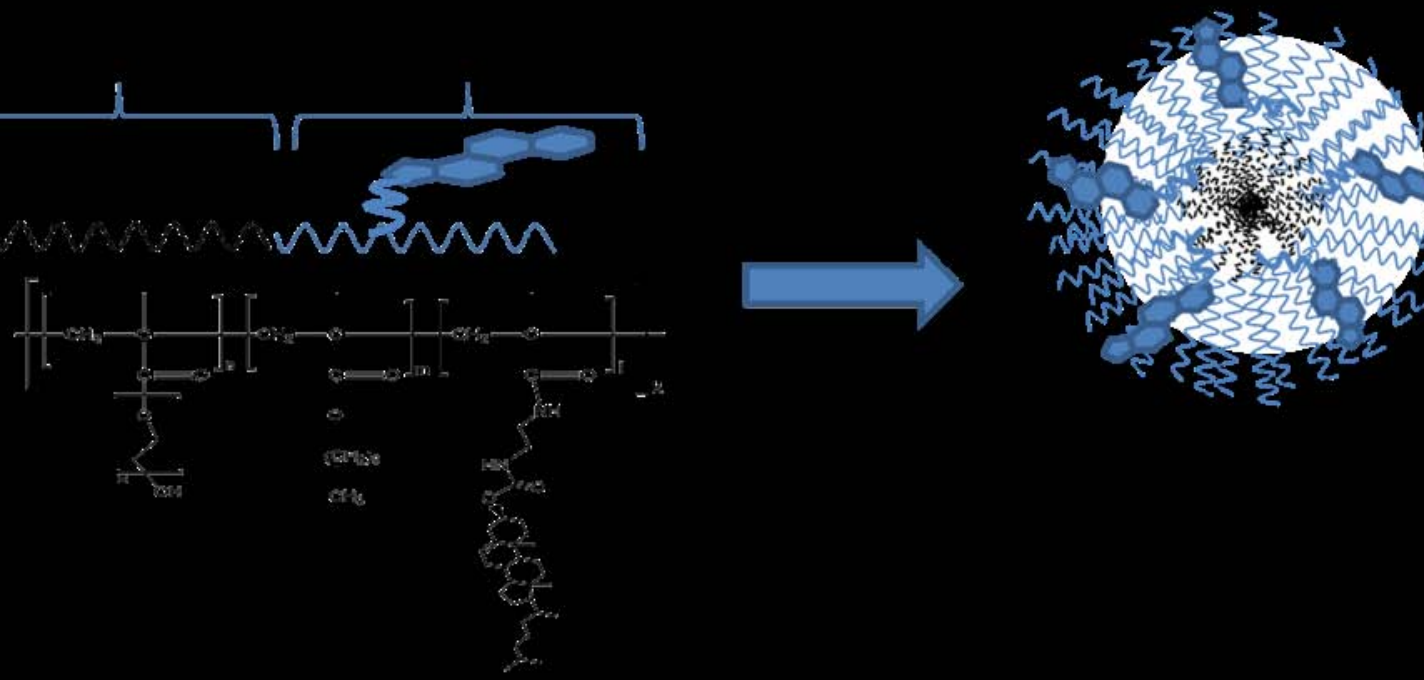

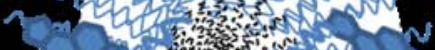

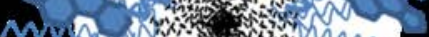
Waw wown

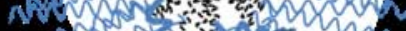

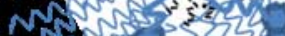

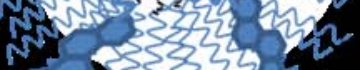

$C>3222$
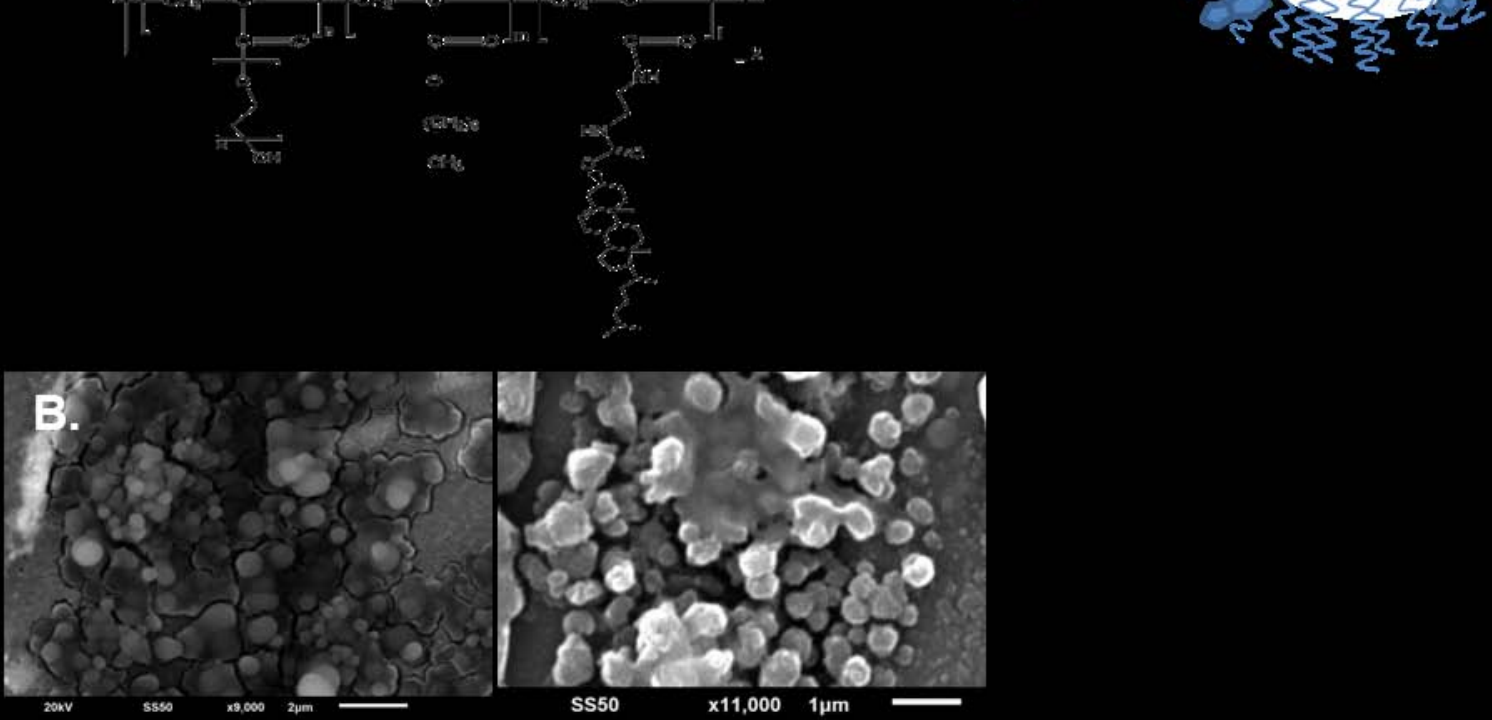